\title{
Comparative analysis of the human hepatic and adipose tissue transcriptomes during LPS-induced inflammation leads to the identification of differential biological pathways and candidate biomarkers
}

Ewa Szalowska ${ }^{1,5^{*}}$, Martijn Dijkstra ${ }^{1}$, Marieke GL Elferink², Desiree Weening ${ }^{1}$, Marcel de Vries ${ }^{1}$, Marcel Bruinenberg ${ }^{3}$, Annemieke Hoek ${ }^{4}$, Han Roelofsen', Geny MM Groothuis ${ }^{2}$ and Roel J Vonk ${ }^{1}$

\begin{abstract}
Background: Insulin resistance (IR) is accompanied by chronic low grade systemic inflammation, obesity, and deregulation of total body energy homeostasis. We induced inflammation in adipose and liver tissues in vitro in order to mimic inflammation in vivo with the aim to identify tissue-specific processes implicated in IR and to find biomarkers indicative for tissue-specific IR.

Methods: Human adipose and liver tissues were cultured in the absence or presence of LPS and DNA Microarray Technology was applied for their transcriptome analysis. Gene Ontology (GO), gene functional analysis, and prediction of genes encoding for secretome were performed using publicly available bioinformatics tools (DAVID, STRING, SecretomeP). The transcriptome data were validated by proteomics analysis of the inflamed adipose tissue secretome.

Results: LPS treatment significantly affected 667 and 483 genes in adipose and liver tissues respectively. The GO analysis revealed that during inflammation adipose tissue, compared to liver tissue, had more significantly upregulated genes, GO terms, and functional clusters related to inflammation and angiogenesis. The secretome prediction led to identification of 399 and 236 genes in adipose and liver tissue respectively. The secretomes of both tissues shared 66 genes and the remaining genes were the differential candidate biomarkers indicative for inflamed adipose or liver tissue. The transcriptome data of the inflamed adipose tissue secretome showed excellent correlation with the proteomics data.

Conclusions: The higher number of altered proinflammatory genes, GO processes, and genes encoding for secretome during inflammation in adipose tissue compared to liver tissue, suggests that adipose tissue is the major organ contributing to the development of systemic inflammation observed in IR. The identified tissue-specific functional clusters and biomarkers might be used in a strategy for the development of tissue-targeted treatment of insulin resistance in patients.
\end{abstract}

\footnotetext{
* Correspondence: ewa.szalowska@wur.nl

${ }^{1}$ Centre for Medical Biomics, University Medical Centre Groningen (UMCG), University of Groningen, Antonius Deusinglaan 1,9713 AV Groningen, The Netherlands

Full list of author information is available at the end of the article
} 


\section{Background}

Adipose tissue is an important metabolic and endocrine organ that secretes numerous biologically active proteins (adipokines) such as leptin, adiponectin, many cytokines, and chemokines [1]. During the development of obesity, adipose tissue undergoes a switch from being mainly a metabolic organ towards an organ that shows substantial pro-inflammatory activity, associated with decreased insulin sensitivity, declined expression of adiponectin and enhanced production of pro-inflammatory cytokines and chemokines. These processes are believed to lead to low-grade inflammation and eventually systemic insulin resistance (IR) and type 2 diabetes (T2D) [2]. However, it is not yet understood how the change in the inflamed adipose tissue transcriptome and secretome leads to the development of IR. In addition to adipose tissue, the liver as an important metabolic and endocrine organ secreting many hormones, chemokines and cytokines, is also affected in obesity $[3,4]$. In a fatty liver, inflammation with activated NF- $\kappa \mathrm{B}$ signaling and upregulated cytokines (IL-6, TNF $\alpha$, and IL-1 $\beta$ ) seems to be a pivotal event leading to the development of liver insulin resistance and non-alcoholic fatty liver disease (NAFLD) which both strongly predispose to the development of systemic IR and T2D. Except for the few proteins known to be produced and secreted by the liver during inflammation little is known about other protein factors which alone or by interacting with the secretome of inflamed adipose tissue could contribute to the development of systemic inflammation and insulin resistance in humans [5-8].

Lipopolysachcaride (LPS) is a compound of the cell wall of Gram-negative bacteria which induces inflammatory reactions and upregulates many cytokines and chemokines via TLRs. Besides its role in inflammation it was shown several times that LPS triggers hyperglycemia and IR in rats and humans [9-12] and induces weight gain and liver IR in mice [13,14].

In our studies, we aimed to identify molecular processes affected during inflammation in human AT and $\mathrm{LT}$ in order to better understand their roles in the inflammation- related development of IR/T2D in vivo. Therefore, we challenged human adipose tissue (omentum) and liver tissue slices with LPS and analyzed gene expression changes by DNA microarray technology and performed Gene Ontology (GO), gene functional classification/clustering analysis by means of publicly available bioinformatics tools: Database for Annotation, Visualization, and Integrated Discovery (DAVID) and Search Tool for the Retrieval of Interacting Genes/Proteins (STRING).

Additionally, we aimed to compare the secretomes of adipose and liver tissues during inflammation in order to better understand how these two organs can contribute to the development of systemic inflammation and IR. The transcriptome data were used to predict genes encoding for secreted proteins, by means of SecretomeP. The comparative analysis of the predicted secretomes led to the identification of differential candidate biomarkers for the inflamed adipose tissue and the inflamed liver tissue. Significantly changed genes detected in the adipose tissue secretome, but not in the inflamed liver tissue secretome were considered as the top candidate biomarkers related to inflammation of adipose tissue and these transcriptome data were confirmed by proteomics analysis of the inflamed adipose tissue culture medium.

The identified biological processes and biomarkers indicative for the inflamed adipose tissue or the inflamed liver tissue might be used for tissue-specific diagnosis of insulin resistance related to inflammation and thereby facilitate more targeted treatment of insulin resistant patients.

\section{Methods}

\section{Human liver tissue}

Human liver tissue $(n=5)$ was obtained and prepared as described previously [15]. The donors of livers were healthy males aged 16-34 years, with BMI 23.1-27.7. The information about the medical history was not available. The research protocols conformed the Helsinki Declaration, were approved by the local Medical Ethical Committee of the UMCG, and patients gave written informed consent to participate in the study.

\section{Preparation and incubation of liver slices}

Human liver slices were prepared and incubated as described previously [15]. Liver slices were incubated at $37^{\circ} \mathrm{C}$ in Williams Medium E in the presence or absence of $100 \mu \mathrm{g} / \mathrm{ml}$ LPS. $24 \mathrm{~h}$ after incubation, slices were frozen in liquid nitrogen and stored at $-80^{\circ} \mathrm{C}$.

\section{Human adipose tissue}

Omentum AT biopsies used for the transcriptome analysis were obtained from 7 Caucasian women undergoing surgery because of benign gynecological problems. The women were in general good health, had no history or symptoms of T2D or inflammatory diseases. The subjects were aged between 30 and 45 years, with BMI ranging from 23 to 29 . The omentum biopsies were taken at the lower edge of the omentum using scissors. The omentum AT biopsy used in proteomics experiment was obtained from a healthy woman aged 59 years, with a BMI of 35.5 The research protocols conformed the Helsinki Declaration, were approved by the local Medical Ethical Committee of the UMCG, and patients gave written informed consent to participate in the study. 
Preparation and incubation of adipose tissue biopsies

The human AT surgical biopsies were processed as described previously [16]. In our studies AT was cultured in the absence/presence of LPS $(100 \mu \mathrm{g} / \mathrm{ml})$ for 24 hours. After the culture time the fat tissue was snap-frozen in liquid nitrogen and stored in $-80^{\circ} \mathrm{C}$ until further processing.

\section{RNA isolation}

RNA was extracted from adipose tissue using RNeasy Lipid Tissue Mini Kit (Qiagen, Venlo, The Netherlands) according to the manufacturer's instructions. RNA extraction from human liver slices was performed as described previously [15]. The RNA concentration was determined by Nano Drop ND-1000 Spectrophotometer (Isogen Ijsselstein, The Netherlands). The quality of total RNA was evaluated by capillary electrophoresis using an Agilent 2100 Bioanalyzer (Agilent Technologies, Palo Alto, Calif.).

\section{Illumina Human WG8-v2 Microarray Analysis}

The Illumina platform was used for the gene expression analysis in adipose tissue. Biotin- labeled cRNA was generated from high-quality total RNA with the Illumina TotalPrep RNA amplification kit (Ambion). Briefly, 50 ng of total RNA was reversely transcribed with an oligo (dT) primer containing a T7 promoter. The first- strand cDNA was used to make the second strand. The purified second-strand cDNA, along with biotin UTPs, was subsequently used to generate biotinylated, antisense RNA of each mRNA in an in vitro transcription reaction. The size distribution profile for the labeled cRNA samples was evaluated by Bioanalyzer. After RNA labeling, $1.5 \mathrm{ug}$ of purified, labeled cRNA from each sample was hybridized at $55^{\circ} \mathrm{C}$ overnight with a Human-8 v2 expression Illumina Beadchip targeting 22000 transcripts. The beadchip was washed the following day. A signal was developed during incubation with Streptavidin-Cy3, and each chip was scanned with an Illumina Bead Array Reader.

The preprocessing of Illumina data was performed using the BeadStudio package with default settings. The background was subtracted and quantile normalization performed. Probes with "absent" signals in all samples (lower than or near to background levels) were removed from further analysis. To identify the differentially expressed genes in LPS treated samples versus controls eBayes test was performed and Benjamini Hochberg test corrected false discovery rate $(F D R) \leq 0.05$. Probes with fold change $\geq 2$ were used for further analysis. The calculations were performed in $\mathrm{R}$, a language for statistical computing and graphics http://www.R-project.org.

\section{Affymetrix Human Genome U133 Plus 2.0 Array Analysis} The Affymetrix platform (55000 transcripts) was used for the liver tissue gene expression analysis. Doublestranded cDNA was synthesized from $1.5 \mu \mathrm{g}$ total RNA using the One-Cycle Target Labeling Kit (Affymetrix Santa Clara, CA), and used as a template for the preparation of biotin-labeled cRNA using the GeneChip IVT Labeling Kit (Affymetrix Santa Clara, CA). Biotinlabeled cRNA was fragmented at $1 \mu \mathrm{g} / \mu \mathrm{l}$ following the manufacturer's protocol. After fragmentation, cRNA (10 $\mu \mathrm{g})$ was hybridized at $45^{\circ} \mathrm{C}$ for 16 hours to the Human Genome U133 Plus 2.0 array (Affymetrix, Santa Clara, CA). Following hybridization, the arrays were washed, stained with phycoerythrin-streptavidin conjugate (Molecular Probes, Eugene, OR), and the signals were amplified by staining the array with biotin-labeled antistreptavidin antibody (Vector Laboratories, Burlingame, CA) followed by phycoerythrin-streptavidin. The arrays were laser scanned with a GeneChip Scanner 3000 7G (Affymetrix, Santa Clara, CA) according to the manufacturer's instructions. Data was saved as raw image file and quantified using GCOS (Affymetrix).

Probe set summarization was performed using the RMA algorithm. Subsequently, baseline subtraction was performed setting the baseline to the median of all samples. To identify the differentially expressed genes in LPS treated samples versus controls an eBayes test was performed and Benjamini Hochberg test corrected false discovery rate $(F D R) \leq 0.05$. Probes with fold change $\geq$ 2 were used for further analysis. The calculations were performed in $\mathrm{R}$, a language for statistical computing and graphics http://www.R-project.org.

\section{Gene Functional Classification Analysis}

The significant transcriptomes of AT and LT were uploaded to Database for Annotation, Visualization, and Integrated Discovery (DAVID) Bioinformatics Resource where the Gene Functional Classification tool was applied to generate clusters of functionally related genes. Additionally, the Functional Annotation Clustering tool was used to generate clusters of overrepresented Gene Ontology (GO) terms [17,18]. The HG-U133 Plus 2 and HUMANREF-8 V2 0 R3 11223162A were used as a background for the GO analysis of liver tissue and adipose tissue respectively. The GO terms after correction for FDR at $\mathrm{p} \leq 0.05$ (Benjamini Hochberg) were selected for further analysis and interpretation.

\section{Gene networks and pathways identification}

The significant transcriptomes of adipose and liver tissues were uploaded to Search Tool for the Retrieval of Interacting Genes/Proteins 8.2 (STRING) where networks based on known and predicted protein-protein 
interactions were built and clustered into functional categories [19].

\section{Secretome prediction}

From the significant transcriptome data obtained for adipose and liver tissues, the secretome prediction was performed with in-house developed software, which retrieved the information about the predicted secretomes from SecretomeP [20]. Genes were considered to belong to the secretome when they encoded for proteins with a predicted signal peptide (present in proteins that are secreted via the classical endoplasmic reticulum/ Golgi-dependent pathway) or when their Neuronal Network $(\mathrm{NN})$ score exceeded the value of 0.5 , which classifies them as secreted via the non-classical pathway. Genes encoding for proteins which did not have a signal peptide nor had the NN-score below 0.5 were considered as genes encoding for intracellular proteins and were discarded from the final secretome analysis.

\section{Adipose tissue culture for the quantitative proteomics analysis}

Quantitative secretome analysis was performed by Isotope-Labeled Amino Acid Incorporation Rates (CILAIR) as described previously [21]. Briefly, $6 \mathrm{~g}$ of fat tissue was used from one patient and divided into six Petri dishes containing $10 \mathrm{ml}$ of lysine-free M199 medium (reference number 22340 Lys-free, Invitrogen) to deplete lysine from other sources (blood in the tissue) and supplemented with $50 \mu \mathrm{g} / \mathrm{ml}$ gentamicin. The tissue was incubated for $24 \mathrm{~h}$. After this period, fresh M199 containing 70 mg/liter 13C-labeled lysine (L-[13C6, 14N2]lysine (Invitrogen) was added to all dishes for the next 24 hours to allow incorporation of the label into newly synthesized proteins, in the absence (3 dishes) or presence (3 dishes) of LPS $(100 \mu \mathrm{g} / \mathrm{ml})$. CILAIR is based on the incorporation rate of $13 \mathrm{C}$-labeled lysine in newly synthesized secreted proteins. If this rate is different between two conditions for a specific protein the change in expression of this protein can be calculated by comparing the heavy/light ratios for the two conditions. After the $24 \mathrm{~h}$ incubation, media were collected and stored at $-80^{\circ} \mathrm{C}$ until further processing. The sample preparation and protein identification by liquid chromatography coupled to mass spectrometry was performed as described previously [21]. ProteinPilot 2.0 software (Applied Biosystems) was used to analyze the mass spectra using the UniprotKB/Swiss-Prot database (release 54, January 2008, 276, 256 entries). The settings used in the analysis were the same as described previously [21].

\section{CILAIR data analysis}

The statistical analysis to detect differences in the secretome of LPS-treated vs. control adipose tissue cultures was performed with in-house generated software that was developed using the open source MOLGENIS toolbox [22]. A two-sided unpaired Student's t-test was applied, and multiple testing correction was performed to control the false discovery rate (FDR) at FDR $<0.05$.

The applied criteria for the proteins predicted to be secreted were the same as described above for the transcriptome data.

\section{Results}

\section{Functional gene annotation analysis}

The transcriptome data analysis revealed that in adipose tissue 667 genes were significantly affected (322 were upregulated and 345 were downregulated) after exposure to LPS. In liver tissue we detected 483 significantly changed genes (283 were upregulated and 200 were downregulated). The overlapping significant transcriptome shared by both tissues consisted of 82 transcripts. The significantly changed genes found in adipose tissue and liver tissue which were not present on both platforms were discarded from further analysis (47 and 42 respectively). Functional gene annotation analysis of significantly upregulated genes in adipose tissue (including the overlapping genes with the liver tissue significant transcriptome) led to the identification of functional groups such as: chemokines; growth and differentiation of hematopoietic precursors; (anti)apoptosis; modulation of immune response; T-, B-, leukocytes, and NK-cells activation, suppression of cytokine signaling (SOCS), extracellular matrix remodeling, and upregulation of numerous transporters, (Additional file 1, Table S1). Within the downregulated gene functional groups we identified: lysosomal/endosomal system activity, basement membrane components, extracellular matrix components, cell adhesion and migration, deoxyribonucleases activity, and detoxification, (Additional file 1, Table S2). A similar analysis was performed for liver tissue and within the upregulated gene functional groups we identified: chemokines; matrix remodeling; (anti)apoptosis; cell adhesion and migration; T- and NKcell activity; and breakdown of extracellular matrix/tissue remodeling, (Additional file 1, Table S3). The functional classification of the downregulated genes led to identification of groups such as: amino acid metabolism, membrane activity, redox/detoxification reactions, cell adhesion and mitochondrial functions, (Additional file 1, Table S4). Additionally, in order to better visualize the similarities and differences between the adipose tissue and liver tissue transcriptomes during inflammation we performed gene functional network reconstruction in STRING. The identified gene functional clusters such as: chemokine signaling, matrix remodelling, SOCS signaling, PPAR $\gamma$ and others are depicted in Figures 1, 2, 3, 4, and 5: the gene functional clusters identified for the 


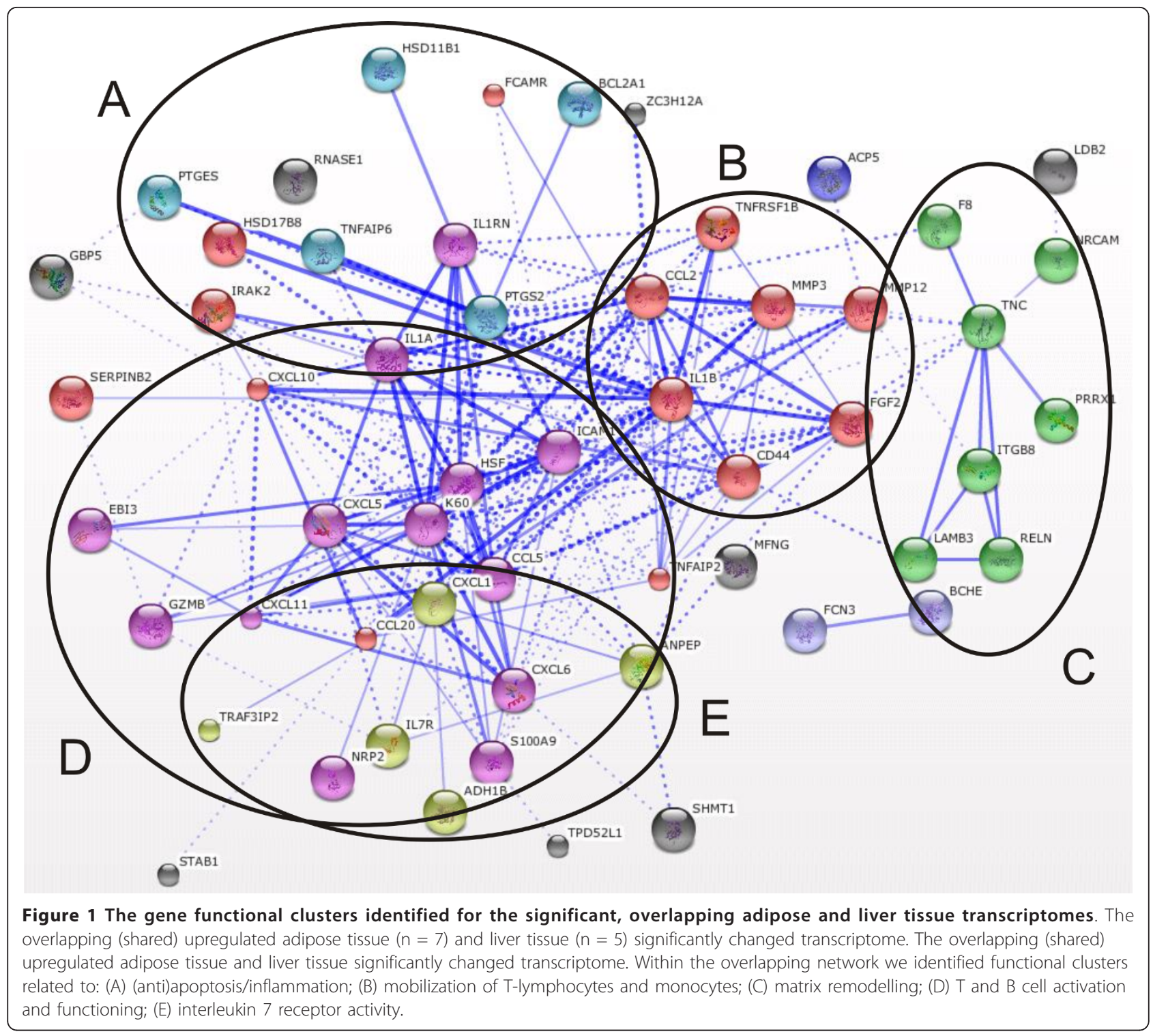

significant, overlapping adipose and liver tissue transcriptomes (Figure 1), the significant, upregulated adipose tissue transcriptome (Figure 2), for the significant, downregulated adipose tissue transcriptome (Figure 3), the significant, upregulated liver tissue transcriptome (Figure 4), and the significant, downregulated liver tissue transcriptome (Figure 5).

\section{Gene Ontology analysis}

Additionally, we performed GO ontology analysis. In adipose tissue we identified more upregulated GO terms compared to liver tissue (106 vs. 36) and for the down-regulated GO terms we detected 2 and 19 in adipose tissue and liver tissue respectively. The significantly upregulated GO terms were divided into broad categories such as "inflammation", "development", "signaling”, "metal ion homeostasis", 'secretion' and "angiogenesis" and within the downregulated GO categories we distinguished: "extracellular region", "amino acid metabolism", and "polysaccharide binding". The GO terms identities within the GO categories are presented in the Additional file 2, Table S1, Additional file 2, Table S2, Additional file 2, Table S3, and Additional file 2, Table S4. Adipose tissue had more upregulated GO terms belonging to "inflammation", "development" and "angiogenesis" compared to liver tissue and had additional terms such as: "signaling", "metal ion homeostasis" and "secretion", (Figure 6; GO analysis of the significant adipose and liver tissues transcriptomes). Within the downregulated GO categories in adipose tissue we detected "extracellular region while in liver tissue- "amino acid metabolism" 


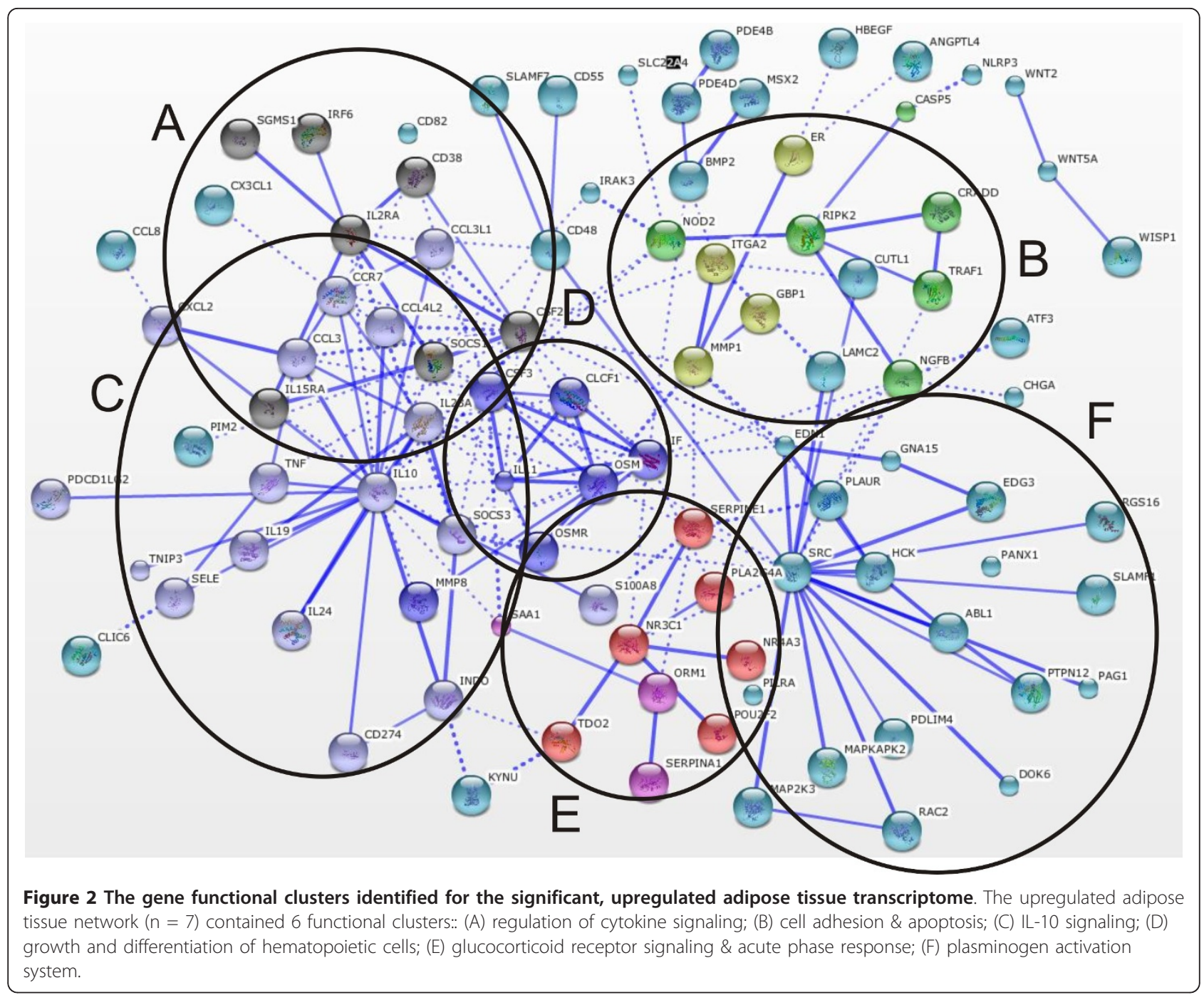

and "polysaccharide binding", (Figure 6; GO analysis of the significant adipose and liver tissues transcriptomes).

When analyzing individual genes within the GO categories, a similar picture emerged -in general a larger number of genes belonging to the identified GO categories was altered in adipose tissue compared to liver tissue (Figure 7 Gene count analysis for the identified GO categories).

The names and Entrez IDs of genes up- and downregulated in both tissues for each GO category are given in Additional file 3, Table S1, Additional file 3, Table S2.

\section{The differentially expressed genes and secretome prediction}

Subsequent analysis of the significant transcriptome data was performed in order to select genes predicted to encode for secreted proteins (the predicted secretome). The analysis revealed that adipose tissue and liver tissue share 66 genes predicted to encode for secreted proteins (46 were upregulated and 20 were downregulated). In the adipose tissue predicted secretome we identified additional 333 significantly changed genes encoding for secreted proteins (138 transcripts were upregulated and 195 -were downregulated) and within the liver tissue predicted secretome we identified 170 different genes encoding for secreted proteins (80 were upregulated and 90 were downregulated).

In our studies we were mostly interested in the upregulated genes as they could be the best candidate biomarkers measurable in human serum. The information about gene expression of the highest upregulated genes in adipose and liver tissues is summarized in Table 1. The presented genes were subdivided in three categories: the first category contained genes which were significantly upregulated in both tissues ( $\mathrm{p} \leq 0.05, \mathrm{FC} \geq$ 2 ) as the best candidate biomarkers for the inflamed adipose and liver tissues. The second category contained 


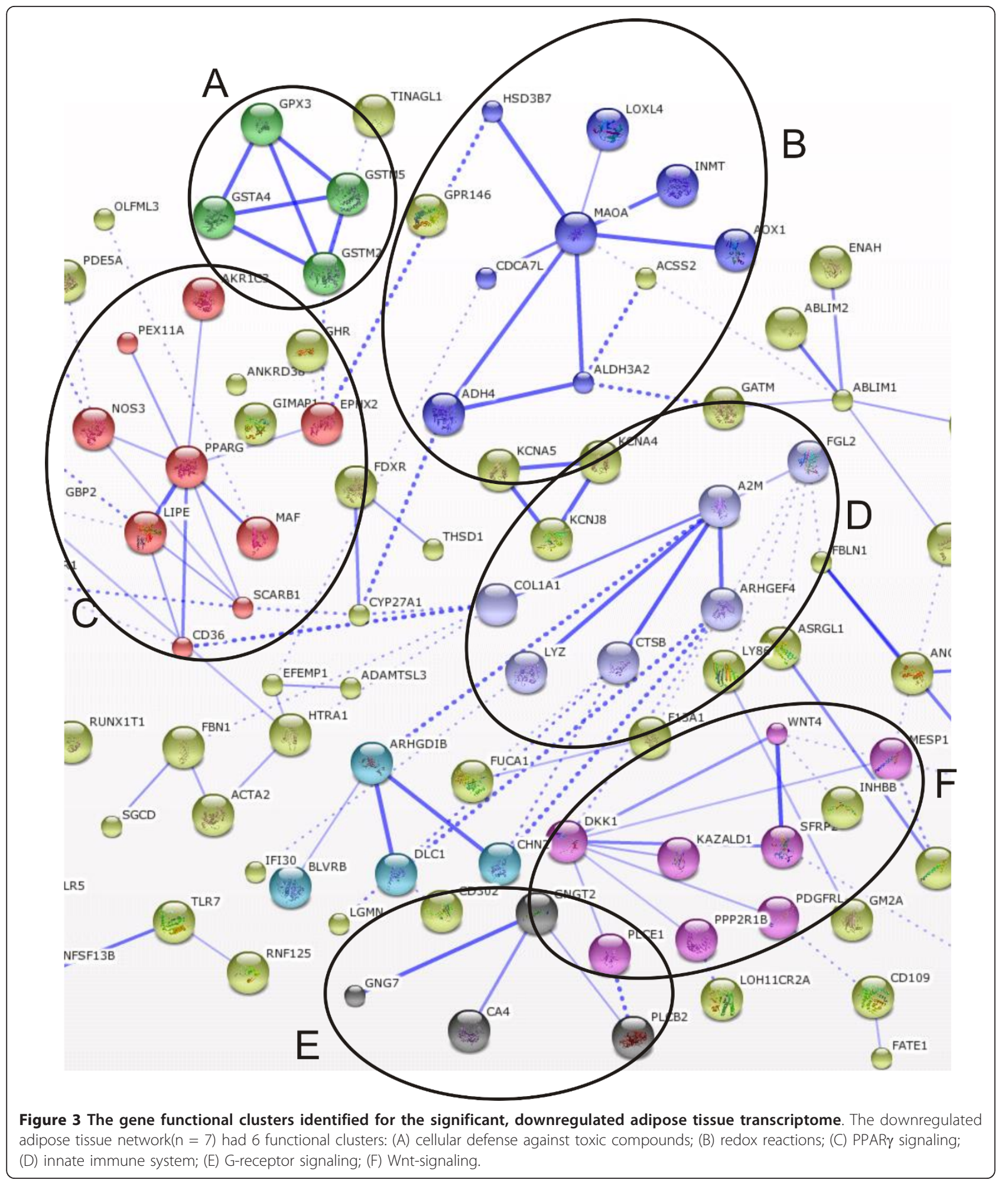

genes significantly upregulated in adipose tissue ( $\mathrm{p} \leq$ $0.05, \mathrm{FC} \geq 2$ ), but not changed in liver tissue, as the best candidate biomarkers for the inflamed adipose tissue. The third category contained genes significantly upregulated in liver tissue ( $\mathrm{p} \leq 0.05, \mathrm{FC} \geq 2$ ) and unchanged in adipose tissue $(p>0.05)$ as the best source of candidate biomarkers for the inflamed liver tissue. The entire list of genes encoding for the 


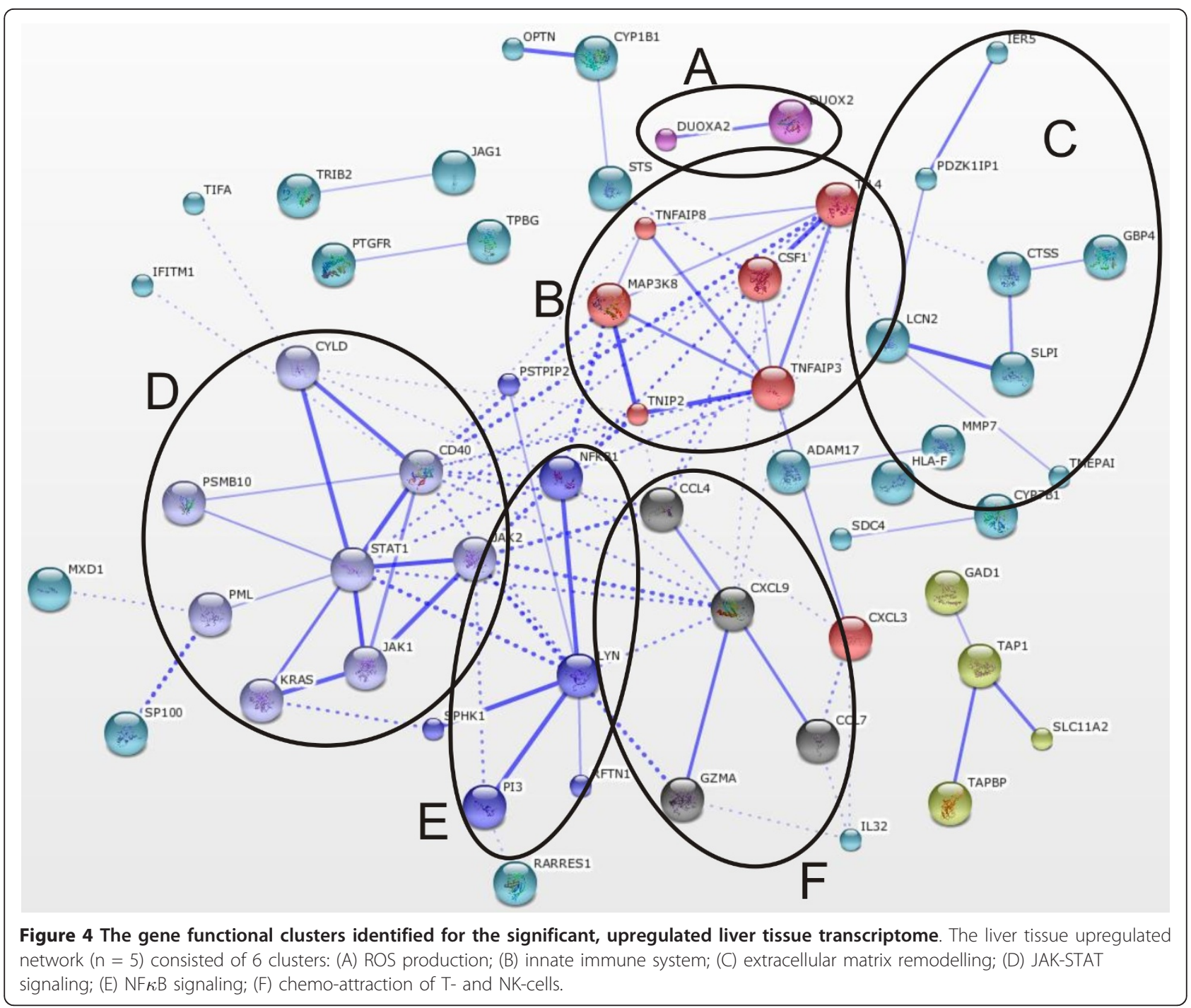

predicted inflammatory secretomes of adipose and liver tissues is given in Additional file 4, Table S1, Additional file 4, Table S2, Additional file 4, Table S3.

\section{Transcriptomics and proteomics data comparison and candidate biomarkers identification}

In order to validate biomarkers related to inflamed adipose tissue, we performed a similar experiment using a quantitative proteomics approach (CILAIR), and analyzed the secreted proteins in the adipose tissue culture media (secretome). In the CILAIR experiment we identified 192 proteins with incorporated label in medium of LPS treated tissue and 209 in medium of untreated adipose tissue. 178 proteins had incorporated label in both conditions and could thus be compared quantitatively. The statistical analysis revealed that 23 proteins were significantly changed in abundance in the secretome by LPS treatment. Comparison with the gene expression data for adipose tissue showed excellent correlation between proteomics and transcriptomics data (Pearson's correlation $\mathrm{r}^{2}=0.78$; Table 2 ). Within the 23 significantly affected proteins we selected those which were significantly affected by LPS in adipose tissue, on both gene and protein level, but not changed in the liver tissue transcriptome, and those proteins were considered as the best candidate biomarkers for inflamed adipose tissue. We propose: LIF, PTX3, MMP1, SERPINE1, and CX3CL1 as the top candidate biomarkers related to the inflamed adipose tissue. The results are summarized in Table 2.

\section{Discussion}

In the present study we evoked LPS induced inflammation in adipose and liver tissues in vitro in order to mimic IR caused by inflammation in vivo. We aimed to compare the changes in the inflamed transcriptomes 


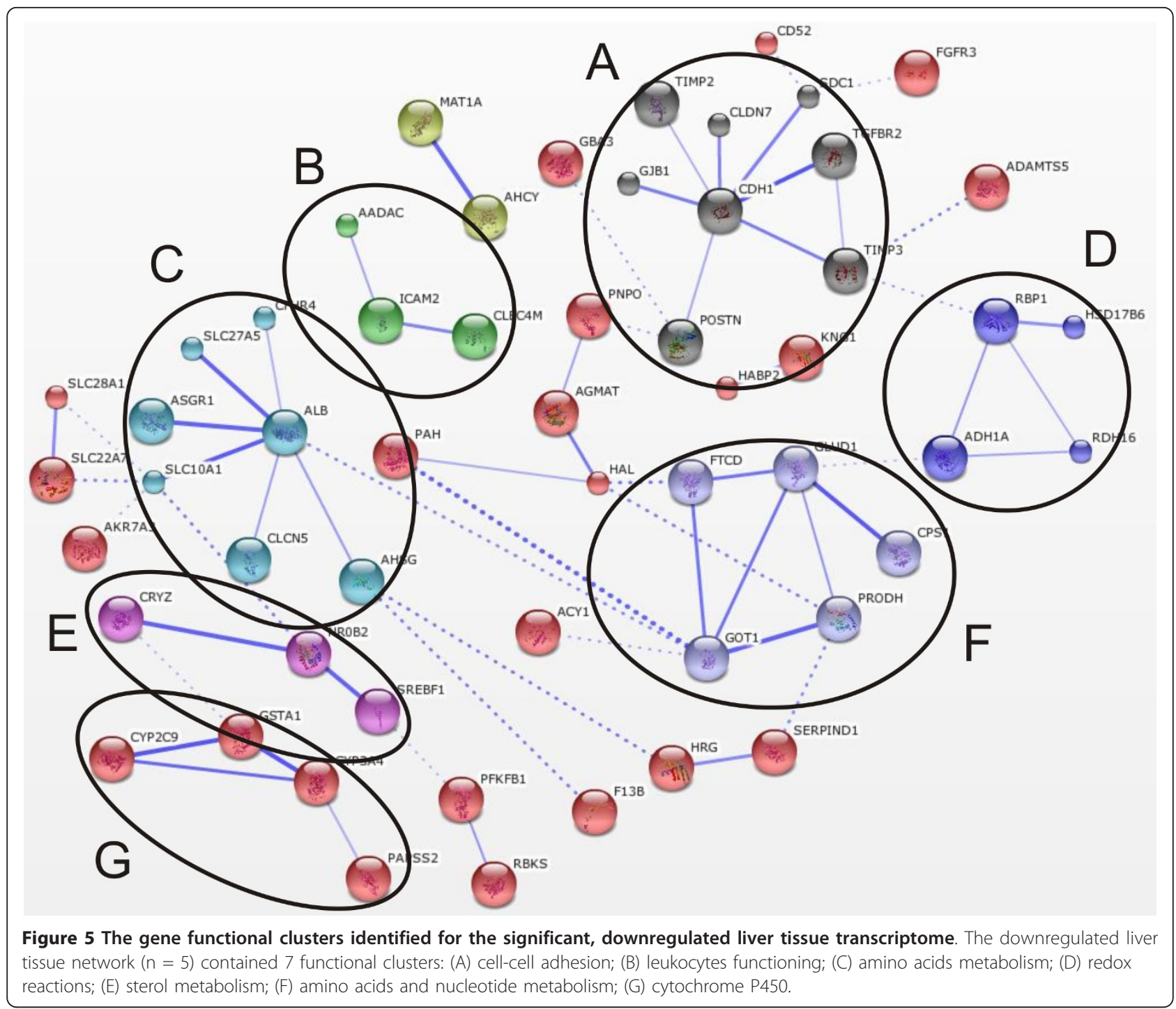

and secretomes of both tissues in order to (1) better understand contribution of the inflamed adipose and liver tissues to the development of insulin resistance and (2) to identify candidate biomarkers indicative for tissue specific inflammation/IR.

The gene functional classification analysis revealed that both adipose and liver tissue share common response mechanisms that are activated during inflammation (chemokine signaling, (anti)apoptosis, extracellular matrix remodelling, adhesion and migration of different immune cells involved in inflammatory reactions). Although functional clustering led to identification of the same functional groups, both tissues had a different set of genes within one functional group, suggesting tissue-specific inflammatory signaling. The significantly upregulated adipose tissue transcriptome contained additional gene functional categories belonging to SOCS and several transporters (Additional file 1, Table S1). The SOCS signaling was shown previously to be involved in induction of insulin resistance during acute inflammation in human adipose tissue [23] and our ex vivo data are in line with these in vivo findings. The analysis of the down regulated functional groups pointed out towards redox/detoxification processes affected in both tissues and mitochondrial functions observed in liver tissue. These processes could contribute to the enhanced reactive oxygen species (ROS) production recognized as one of the mechanisms implicated in the development of IR/T2D [13]. Furthermore, adipose tissue had downregulated genes involved in the extracellular matrix activity which is involved in multiple processes including modulation of immune responses. In liver tissue downregulation of genes involved in amino acid metabolism and polysaccharide 


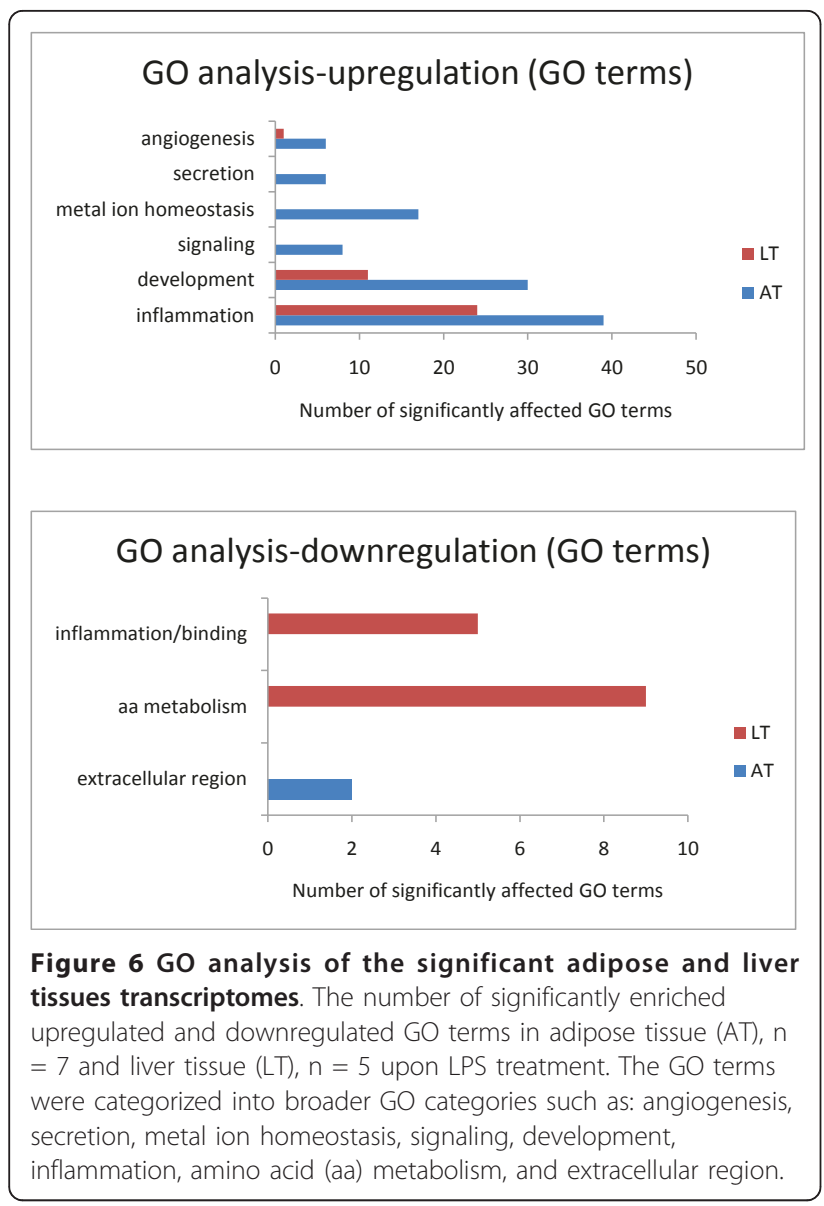

binding were observed. There are reports about changed amino acids concentrations in animal models of obesity and obese humans [24,25], however interpretation of this ex vivo finding in relation to these reports is not unequivocal.

The additional network identification for the common (overlapping) and differential adipose and liver tissue transcriptomes was in line with the data obtained from the gene functional analysis and distinguished the common and differential networks. Moreover, several of these networks were described previously in the literature for their role in induction of IR thereby supporting our model system to study the inflammation related insulin resistance in vivo. For example, in our study we found upregulated chemokine signaling and matrix remodelling in both adipose and liver tissues which were also previously linked to the development of IR in vivo [26,27]. SOCS signaling is implicated in induction of IR [28-30] and similarly it was found by us to be upregulated by LPS in adipose tissue ex vivo. The decreased PPAR $\gamma$ expression in adipose tissue is recognized as one of the events associated with IR and occurred in our ex vivo studies as well $[31,32]$. Similarly

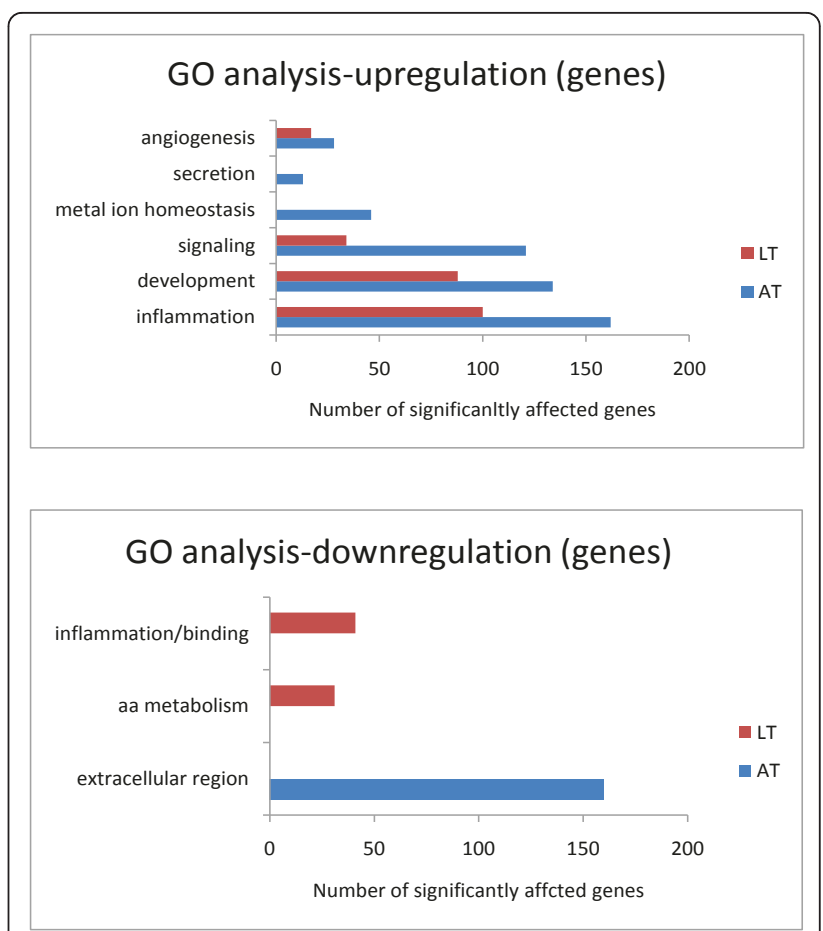

Figure 7 Gene count analysis for the identified GO categories. Number of genes significantly upregulated and downregulated in adipose tissue (AT), $n=7$, and liver tissue (LT), $n=5$ within $G O$ categories (angiogenesis, secretion, metal ion homeostasis, signaling, development, inflammation, amino acid (aa) metabolism, and extracellular region).

upregulated Jak-STAT and NF $\kappa$ B signaling identified previously in IR liver [33] was present in our experiments.

The GO analysis and gene count revealed that adipose tissue had more LPS-induced upregulated GO terms and genes related primarily to "inflammation", "angiogenesis", and "development". Moreover, the predicted secretome studies showed that the adipose tissue predicted inflammatory secretome is more abundant compared to the liver tissue secretome. This observation indicates that adipose tissue is more active during inflammation, compared to liver tissue, and supports the hypothesis that adipose tissue plays the major role in the development of inflammation-related IR [2].

The reason for different responses of the adipose and liver tissues could be due to a different expression of TLR4 and other components involved in signal transduction via TLR4 (LBP, CD14, TREM1), but unfortunately in our studies we can not directly compare expression values between the adipose tissue and the liver data (two different DNA microarray platforms were used). Nevertheless, we observed that the expression patterns/ratios of all the TLR4 signaling molecules in both tissues were very similar (data not shown). 
Table 1 The most differential predicted secretome of adipose and liver tissues

\begin{tabular}{|c|c|c|c|c|c|c|c|c|c|c|c|c|c|c|}
\hline ACC. & NAME4 & GENE & $\begin{array}{l}\text { AT } \\
\text { FC }\end{array}$ & $\begin{array}{l}\text { AT } p \\
\text { value }\end{array}$ & $\begin{array}{l}\text { AT avg } \\
\text { - LPS }\end{array}$ & $\begin{array}{l}\text { AT avg } \\
+ \text { LPS }\end{array}$ & $\begin{array}{l}\text { AT std } \\
\text { - LPS }\end{array}$ & $\begin{array}{l}\text { AT std } \\
+ \text { LPS } \\
\end{array}$ & $\begin{array}{l}\mathrm{LT} \\
\mathrm{FC}\end{array}$ & $\begin{array}{l}\text { LT } p \\
\text { value }\end{array}$ & $\begin{array}{l}\text { LT avg } \\
\text { - LPS }\end{array}$ & $\begin{array}{l}\text { LT avg } \\
+ \text { LPS }\end{array}$ & $\begin{array}{l}\text { LT std } \\
\text { - LPS }\end{array}$ & $\begin{array}{l}\text { LT std } \\
+ \text { LPS } \\
\end{array}$ \\
\hline P01584 & INTERLEUKIN 1, BETA & IL1B & $\underline{20}$ & $1,18 \mathrm{E}-06$ & 584,3 & 11733,8 & 496,8 & 3295,7 & 100 & 0,0002 & 9,5 & 957,6 & 17,6 & 305,3 \\
\hline P10147 & CHEMOKINE (C-C MOTIF) LIGAND 3 & CCL3 & 19.8 & $2,0 \mathrm{E}-07$ & 239,3 & 4732,6 & 160,7 & 2239,1 & 10.7 & 0,0088 & 48,7 & 521,6 & 55,4 & 226,4 \\
\hline Q96DR8 & SMALL BREAST EPITHELIAL MUCIN & MUCL1 & $\overline{17.4}$ & $5,5 \mathrm{E}-05$ & 36,4 & 607,9 & 20,9 & 759,2 & $\overline{5.8}$ & 0,0008 & 5,1 & 30,0 & 2,3 & 14,8 \\
\hline P18510 & INTERLEUKIN 1 RECEPTOR ANTAGONIST & IL1RN & $\overline{12.5}$ & $9,4 \mathrm{E}-06$ & 16,6 & 207,4 & 6,3 & 164,7 & $\overline{6.5}$ & 0,0148 & 118,4 & 768,3 & 127,8 & 1132,3 \\
\hline P78556 & CHEMOKINE (C-C MOTIF) LIGAND 20 & CCL20 & $\overline{11.4}$ & $7,2 \mathrm{E}-06$ & 1602,6 & 18245,7 & 1844,3 & 2070,8 & $\overline{7.5}$ & 0,0199 & 1149,2 & 8631,9 & 306,4 & 1263,2 \\
\hline P16619 & CHEMOKINE (C-C MOTIF) LIGAND 3-LIKE 1 & CCL3L1 & $\underline{10.7}$ & $3,4 \mathrm{E}-07$ & 49,7 & 1715,4 & 38,6 & 894,1 & $\underline{34.5}$ & 0,0088 & 48,7 & 521,6 & 55,4 & 226,4 \\
\hline P42830 & CHEMOKINE (C-X-C MOTIF) LIGAND 5 & CXCL5 & $\underline{7.8}$ & $1,5 \mathrm{E}-04$ & 735,9 & 5489,8 & 1215,8 & 2385,3 & 30.3 & 0,0000 & 13,9 & 330,5 & 1,9 & 23,3 \\
\hline P35354 & PROSTAGLANDIN-ENDOPEROXIDE SYNTHASE 2 & PTGS2 & $\underline{6.8}$ & $5,1 \mathrm{E}-05$ & 1530,5 & 10373,9 & 1772,5 & 2532,4 & $\underline{7.9}$ & 0,0478 & 39,9 & 315,1 & 3,9 & 63,5 \\
\hline P13501 & CHEMOKINE (C-C MOTIF) LIGAND 5/RANTES & CCL5 & $\overline{6.3}$ & $1,4 \mathrm{E}-06$ & 252,5 & 1588,3 & 190,4 & 458,9 & $\overline{68}$ & 0,0002 & 15,8 & 1074,0 & 17,0 & 1425,3 \\
\hline P05120 & SERPIN PEPTIDASE INHIBITOR & SERPINB2 & $\underline{6}$ & 1, 1E-06 & 1825,8 & 10909,0 & 856,7 & 2503,1 & $\underline{8}$ & 0,0022 & 25,0 & 200,7 & 37,0 & 104,9 \\
\hline P01583 & INTERLEUKIN 1, ALPHA & IL1A & $\underline{5.8}$ & 4, 4E-04 & 343,2 & 1979,4 & 211,1 & 820,6 & $\underline{4.3}$ & 0,0043 & 7,3 & 32,1 & 2,3 & 4,2 \\
\hline 014625 & CHEMOKINE (C-X-C MOTIF) LIGAND 11 & CXCL11 & $\underline{5.4}$ & $1,3 \mathrm{E}-03$ & 19,1 & 102,5 & 15,9 & 63,2 & $\underline{20.4}$ & 0,0269 & 10,5 & 214,6 & 17,2 & 1379,4 \\
\hline P05231 & INTERLEUKIN 6 (INTERFERON, BETA 2) & IL6 & $\underline{4.5}$ & $2,1 \mathrm{E}-05$ & 4702,1 & 21313,8 & 3820,2 & 1972,7 & $\overline{17.8}$ & 0,0097 & 40,6 & 722,6 & 52,8 & 703,0 \\
\hline P08254 & MATRIX METALLOPEPTIDASE 3 & MMP3 & $\underline{4}$ & $5,5 \mathrm{E}-04$ & 1333,4 & 5331,4 & 1458,8 & 1982,5 & $\underline{20.6}$ & 0,0377 & 12,2 & 251,5 & 115,5 & 725,9 \\
\hline P09038 & FIBROBLAST GROWTH FACTOR 2 (BASIC) & FGF2 & 3.7 & $7,1 \mathrm{E}-04$ & 173,4 & 642,5 & 165,2 & 200,0 & $\overline{3.5}$ & 0,0020 & 13,7 & 48,4 & 5,5 & 32,0 \\
\hline P39900 & $\begin{array}{c}\text { MATRIX METALLOPEPTIDASE } 12 \text { (MACROPHAGE } \\
\text { ELASTASE) }\end{array}$ & MMP12 & $\underline{3.7}$ & $1,5 \mathrm{E}-04$ & 22,1 & 81,7 & 8,9 & 41,1 & $\underline{5.8}$ & 0,0220 & 19,0 & 110,8 & 31,8 & 102,9 \\
\hline P09341 & CHEMOKINE (C-X-C MOTIF) LIGAND 1 & CXCL1 & $\underline{3}$ & $1,0 \mathrm{E}-03$ & 4666, 1 & 14183,2 & 5268,4 & 3237,7 & $\underline{23.5}$ & 0,0013 & 70,1 & 1648,1 & 45,5 & 615,2 \\
\hline P02778 & CHEMOKINE (C-X-C MOTIF) LIGAND 10 & CXCL10 & $\underline{2.9}$ & $1,4 \mathrm{E}-03$ & 361,5 & 1045,7 & 248,5 & 461,4 & $\underline{17}$ & 0,0431 & 72,3 & 1234,9 & 4543,9 & 297,8 \\
\hline P80162 & CHEMOKINE (C-X-C MOTIF) LIGAND 6 & CXCL6 & $\underline{2.8}$ & 1, 3E-03 & 2632,1 & 7420,4 & 2720,0 & 1531,1 & $\underline{22}$ & 0,0033 & 20,4 & 447,3 & 49,8 & 174,3 \\
\hline P10144 & GRANZYME B & GZMB & $\underline{2.8}$ & $5,1 \mathrm{E}-04$ & 31,8 & 87,9 & 8,5 & 38,9 & $\underline{6.1}$ & 0,0253 & 11,9 & 73,1 & 7,6 & 91,3 \\
\hline O60462 & NEUROPILIN 2 & NRP2 & $\underline{2.6}$ & $7,0 \mathrm{E}-06$ & 25,0 & 65,5 & 9,0 & 7,5 & $\overline{2.6}$ & 0,0211 & 27,9 & 72,7 & 4,8 & 15,3 \\
\hline P10145 & INTERLEUKIN 8 & IL8 & $\underline{2.5}$ & $2,1 \mathrm{E}-03$ & 9738,0 & 23999,7 & 7532,4 & 1532,3 & $\underline{6}$ & 0,0038 & 358,9 & 4271,3 & 480,9 & 1244,2 \\
\hline P13500 & CHEMOKINE (C-C MOTIF) LIGAND 2 & CCL2 & $\underline{2.3}$ & $5,1 \mathrm{E}-06$ & 5528,4 & 12745,4 & 1561,6 & 1659,7 & $\underline{3.7}$ & 0,0435 & 726,0 & 2675,4 & 321,4 & 366,3 \\
\hline P16581 & SELECTIN E (ENDOTHELIAL ADHESION MOLECULE 1) & SELE & $\overline{105.1}$ & 1, 9E-06 & 5,3 & 558,7 & 4,9 & 191,7 & $\overline{4,6}$ & 0,6116 & 6,9 & 31,4 & 4,7 & 31,9 \\
\hline P04141 & COLONY STIMULATING FACTOR 2 & CSF2 & 82.5 & 1, 7E-07 & 9,0 & 742,5 & 12,3 & 402,4 & 1,6 & 0,4180 & 1,6 & 2,7 & 5,2 & 2,5 \\
\hline Q9BYE3 & LATE CORNIFIED ENVELOPE 3D & LCE3D & $\underline{46}$ & $1,2 \mathrm{E}-05$ & $-2,7$ & 70,3 & 4,1 & 103,9 & $-1,2$ & 0,7820 & 8,2 & 7,0 & 5,1 & 6,7 \\
\hline P02763 & OROSOMUCOID 1 & ORM1 & $\underline{26.6}$ & $2,3 \mathrm{E}-03$ & 12,4 & 329,5 & 8,8 & 470,6 & 1,0 & 0,7173 & 4506,7 & 4609,2 & 1108,8 & 582,4 \\
\hline O14944 & EPIREGULIN & EREG & 25 & $1,8 \mathrm{E}-06$ & $-3,1$ & 17,1 & 4,0 & 8,7 & $-2,0$ & 0,8984 & 2,8 & 1,3 & 2,0 & 4,5 \\
\hline P22894 & $\begin{array}{c}\text { MATRIX METALLOPEPTIDASE } 8 \text { (NEUTROPHIL } \\
\text { COLLAGENASE) }\end{array}$ & MMP8 & $\underline{22.2}$ & 1, 3E-03 & 2,3 & 51,3 & 5,7 & 48,1 & 1,5 & 0,4560 & 10,6 & 15,9 & 9,7 & 18,5 \\
\hline Q00604 & NORRIE DISEASE (PSEUDOGLIOMA) & NDP & $\underline{19.5}$ & $3,8 \mathrm{E}-07$ & 15,1 & 295,4 & 13,4 & 165,2 & 1,3 & 0,9185 & 1,5 & 1,9 & 1,6 & 2,5 \\
\hline P07357 & COMPLEMENT COMPONENT 8, ALPHA POLYPEPTIDE & $\mathrm{C} 8 \mathrm{~A}$ & $\overline{18.6}$ & $3,6 \mathrm{E}-04$ & 18,6 & 345,7 & 21,4 & 179,7 & $-1,6$ & 0,5130 & 780,6 & 481,8 & 421,3 & 165,0 \\
\hline P78423 & FRACTALCINE & CX3CL1 & $\underline{6.4}$ & $5,6 \mathrm{E}-07$ & 97,1 & 617,8 & 29,9 & 285,0 & 9.9 & 0,6235 & 23.4 & 232.5 & 14.3 & 431.9 \\
\hline P01375 & $\begin{array}{c}\text { TUMOR NECROSIS FACTOR (TNF SUPERFAMILY, } \\
\text { MEMBER 2) }\end{array}$ & TNF & $\underline{6}$ & $3,5 \mathrm{E}-10$ & 28,8 & 173,4 & 5,5 & 30,3 & 1,6 & 0,9980 & 7,8 & 12,8 & 4,4 & 7,5 \\
\hline Q9UHD0 & INTERLEUKIN 19 & IL19 & 5.6 & 9, 7E-06 & 6,2 & 34,9 & 3,0 & 13,1 & 1,8 & 0,5200 & $-2,0$ & $-3,4$ & 3,0 & 4,8 \\
\hline
\end{tabular}


Table 1 The most differential predicted secretome of adipose and liver tissues (Continued)

\begin{tabular}{|c|c|c|c|c|c|c|c|c|c|c|c|c|c|c|}
\hline P26022 & $\begin{array}{c}\text { PENTRAXIN-RELATED GENE, RAPIDLY INDUCED BY IL-1 } \\
\text { BETA }\end{array}$ & PTX3 & $\underline{4}$ & $1,0 \mathrm{E}-04$ & 992,2 & 4000,0 & 614,4 & 1504,4 & 2,1 & 0,6562 & 7,5 & 15,5 & 7,2 & 7,8 \\
\hline P03956 & $\begin{array}{c}\text { MATRIX METALLOPEPTIDASE } 1 \text { (INTERSTITIAL } \\
\text { COLLAGENASE) }\end{array}$ & MMP1 & 3.4 & $3,0 \mathrm{E}-04$ & 2662,1 & 8995,1 & 3099,1 & 1471,0 & 1,0 & 0,5981 & 928,4 & 968,5 & 1473,1 & 441,9 \\
\hline Q9BY76 & ANGIOPOIETIN-LIKE 4 & ANGPTL4 & 3.2 & $2,9 \mathrm{E}-03$ & 83,8 & 268,7 & 45,7 & 139,2 & 2,0 & 0,5980 & 70,6 & 137,9 & 34,0 & 156,1 \\
\hline P19875 & CHEMOKINE (C-X-C MOTIF) LIGAND 2 & CXCL2 & 3.1 & 7, 3E-04 & 1753,9 & 5471,3 & 1121,4 & 1569,5 & 1,4 & 0,4725 & 13,7 & 19,1 & 5,3 & 5,8 \\
\hline P05121 & $\begin{array}{l}\text { SERPIN PEPTIDASE INHIBITOR/PLASMINOGEN } \\
\text { ACTIVATOR INHIBITOR TYPE 1) MEMBER } 1\end{array}$ & $\begin{array}{l}\text { SERPINE1/ } \\
\text { pai1 }\end{array}$ & 3 & $6,1 \mathrm{E}-04$ & 3110,0 & 9426,1 & 2165,8 & 2364,8 & 1,7 & 0,7450 & 64,6 & 108,5 & 29,1 & 81,8 \\
\hline P10124 & PROTEOGLYCAN 1, SECRETORY GRANULE & SRGN & 2.7 & $3,2 \mathrm{E}-05$ & 3141,4 & 8426,4 & 1107,6 & 2008, 1 & 1,1 & 1,0000 & 3,4 & 3,6 & 3,0 & 1,5 \\
\hline Q96RQ9 & INTERLEUKIN 4 INDUCED 1 & IL4I1 & $\overline{2.4}$ & $2,4 \mathrm{E}-03$ & 132,4 & 318,9 & 73,6 & 149,7 & $-1,6$ & 0,7500 & $-1,2$ & $-0,8$ & 3,5 & 5,1 \\
\hline Q9Y5U4 & INSULIN INDUCED GENE 2 & INSIG2 & $\overline{2.3}$ & $8,5 \mathrm{E}-04$ & 316,7 & 722,0 & 129,6 & 225,9 & $-1,2$ & 0,8880 & 94,3 & 79,9 & 38,4 & 11,1 \\
\hline P12643 & BONE MORPHOGENETIC PROTEIN 2 & BMP2 & $\overline{2.2}$ & $3,4 \mathrm{E}-04$ & 1131,3 & 2465,7 & 472,0 & 655,5 & 1,7 & 0,6915 & 91,6 & 158,3 & 103,2 & 87,3 \\
\hline P02735 & SERUM AMYLOID A1 & SAA1 & $\overline{2.2}$ & $2,2 \mathrm{E}-03$ & 355,1 & 778,1 & 165,9 & 246,5 & 1,1 & 0,9120 & 4896,1 & 5144,0 & 564,6 & 238,5 \\
\hline Q07325 & CHEMOKINE (C-X-C MOTIF) LIGAND 9 & CXCL9 & $\overline{1.8}$ & $5,5 E-02$ & 207,1 & 376,4 & 231,9 & 233,9 & 69.3 & 0,0009 & 33,0 & 2288,5 & 66,7 & 3090,5 \\
\hline P19876 & CHEMOKINE (C-X-C MOTIF) LIGAND 3 & CXCL3 & $\overline{3.6}$ & $9,6 \mathrm{E}-03$ & 15,5 & 56,0 & 7,9 & 29,7 & $\overline{20.6}$ & 0,0050 & 28,1 & 587,5 & 8,9 & 300,0 \\
\hline 095633 & FOLLISTATIN-LIKE 3 (SECRETED GLYCOPROTEIN) & FSTL3 & $\overline{1}$ & 9, 3E-01 & 687,0 & 665,4 & 224,2 & 136,2 & $\overline{15.1}$ & 0,0036 & 32,8 & 495,5 & 86,8 & 378,1 \\
\hline Q13113 & PDZK1 INTERACTING PROTEIN 1 & PDZK1IP1 & 1.9 & 2, 3E-01 & 43,0 & 84,2 & 25,9 & 54,7 & 12.9 & 0,0010 & 13,0 & 169,4 & 51,6 & 168,3 \\
\hline Q9NRD8 & DUAL OXIDASE 2 & DUOX2 & $\overline{-2}$ & 3, 5E-01 & 4,9 & 2,3 & 2,9 & 3,8 & $\overline{5.5}$ & 0,0084 & 77,2 & 428,5 & 49,2 & 154,2 \\
\hline Q8WWX9 & SELENOPROTEIN M & SELM & $\overline{1.6}$ & $5,2 \mathrm{E}-03$ & 2336,5 & 3877,9 & 840,8 & 945,4 & $\overline{3.9}$ & 0,0025 & 114,1 & 445,5 & 37,0 & 79,2 \\
\hline O94808 & $\begin{array}{c}\text { GLUTAMINE-FRUCTOSE-6-PHOSPHATE TRANSAMINASE } \\
2\end{array}$ & GFPT2 & $\overline{1.7}$ & 1, 3E-04 & 2797,3 & 4808,3 & 419,1 & 945,3 & $\overline{3.6}$ & 0,0019 & 15,1 & 54,6 & 3,3 & 2,7 \\
\hline P13164 & $\begin{array}{l}\text { INTERFERON INDUCED TRANSMEMBRANE PROTEIN } 1 \\
\qquad(9-27)\end{array}$ & IFITM1 & -1.1 & -01 & 1 & 2 & 1 & 68 & $\underline{3.5}$ & 0,0435 & 2 & 1318,2 & 462,2 & 466,0 \\
\hline P09603 & COLONY STIMULATING FACTOR 1 (MACROPHAGE) & CSF1 & $-\underline{1.6}$ & 3, 0E-02 & 128,4 & 73,4 & 53,5 & 28,0 & 3.3 & 0,0056 & 73,4 & 242,7 & 19,3 & 118,7 \\
\hline P12544 & GRANZYME A & GZMA & $\overline{-1.4}$ & 2, 2E-01 & 123,1 & 85,7 & 55,7 & 25,5 & $\overline{3.3}$ & 0,0215 & 6,7 & 21,9 & 3,6 & 27,1 \\
\hline P25774 & CATHEPSIN S & CTSS & $\overline{1.4}$ & $1,2 \mathrm{E}-02$ & 135,5 & 194,8 & 43,5 & 31,0 & $\underline{3.2}$ & 0,0168 & 270,5 & 881,9 & 86,8 & 355,9 \\
\hline P24001 & INTERLEUKIN 32 & IL32 & $\overline{1.6}$ & $5,0 \mathrm{E}-06$ & 551,7 & 888,2 & 42,1 & 121,3 & $\underline{3}$ & 0,0061 & 2723,6 & 8331,0 & 668,1 & 472,2 \\
\hline P31431 & SYNDECAN 4 (AMPHIGLYCAN, RYUDOCAN) & SDC4 & $\overline{1.9}$ & $1,5 \mathrm{E}-02$ & 1049, 2 & 1962, 3 & 453,7 & 796,4 & $\underline{2.7}$ & 0,0111 & 1141,2 & 3088,8 & 160,0 & 643,0 \\
\hline P03973 & SECRETORY LEUKOCYTE PEPTIDASE INHIBITOR & SLPI & $\overline{-1.4}$ & $1,0 E+00$ & 1063,8 & 755,9 & 946,2 & 387,2 & $\overline{2.7}$ & 0,0050 & 1505,1 & 4153,1 & 255,9 & 660,6 \\
\hline P09237 & MATRIX METALLOPEPTIDASE 7 (MATRILYSIN, UTERINE) & MMP7 & $\overline{-1.6}$ & 4, 2E-01 & 7,9 & 4,5 & 13,2 & 15,1 & $\overline{2.6}$ & 0,0244 & 8,7 & 22,8 & 12,3 & 34,0 \\
\hline Q5VY09 & IMMEDIATE EARLY RESPONSE 5 & IER5 & $\overline{1.6}$ & 4, 7E-03 & 471,5 & 780,8 & 99,5 & 258,3 & $\overline{2.5}$ & 0,0215 & 139,5 & 347,3 & 79,7 & 90,2 \\
\hline O75976 & CARBOXYPEPTIDASE D & CPD & $\overline{1.3}$ & 1, 2E-01 & 761,1 & 1012,4 & 282,7 & 315,0 & $\overline{2.2}$ & 0,0335 & 54,8 & 118,9 & 47,3 & 51,3 \\
\hline
\end{tabular}

Fold change (FC) for the highest and significantly upregulated genes $(\mathrm{p} \leq 0.05)$ upon LPS treatment $(+\mathrm{LPS})$ compared to control (-LPS) in adipose tissue (AT), $n=7$ and liver tissue (LT) $n=5$ are indicated in bold and are underlined. FCs for not significantly changed genes in both tissues $(p>0.05)$ are in italics. Additionally, information about average (avg) gene expression value and it's standard deviation (std) for both AT and $\mathrm{LT}$ is given. 
Table 2 Significantly changed secreted proteins in adipose tissue culture media and the corresponding identified genes in adipose tissue and liver tissue upon LPS-treatment

\begin{tabular}{|c|c|c|c|c|c|c|c|c|}
\hline NAME & SYMBOL & $\begin{array}{l}\text { AT FC- } \\
\text { protein }\end{array}$ & $\begin{array}{l}\text { avg AT LPS } \\
+ \text { protein }\end{array}$ & $\begin{array}{l}\text { avg AT } \\
\text { LPS- } \\
\text { protein }\end{array}$ & $\begin{array}{l}\text { std AT LPS } \\
+ \text { protein }\end{array}$ & $\begin{array}{l}\text { std AT } \\
\text { LPS- } \\
\text { protein }\end{array}$ & $\begin{array}{l}\text { AT ( } p \text { val.) FC- } \\
\text { transcriptome }\end{array}$ & $\begin{array}{c}\text { LT ( } p \text { val.) } \\
\text { FC- transcriptome }\end{array}$ \\
\hline Leukemia inhibitory factor & LIF & 2.3 & 6,6 & 2,9 & 0,22 & 0,41 & $(0,000) 7,2$ & (ns) 2.9 \\
\hline Fractalkine & $\mathrm{CX} \overline{3 \mathrm{CL} 1}$ & $\overline{4.3}$ & 4,3 & 1,0 & 0,24 & 0,10 & $\overline{(0,000) 6.4}$ & 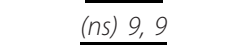 \\
\hline Tumor necrosis factor & TNF & $\overline{3.8}$ & 4,8 & 1,3 & 0,95 & 0,15 & $(0,000) 6$ & $\overline{\text { (ns) } 7.7}$ \\
\hline $\begin{array}{c}\text { Plasminogen activator } \\
\text { inhibitor } 2\end{array}$ & SERPINB2 & 3.1 & 2,6 & 0,8 & 0,41 & 0,05 & $\overline{(0,000) 6}$ & $(\overline{0,002)} 8$ \\
\hline Interleukin-6 & IL6 & 1.6 & 6,9 & 4,7 & 0,31 & 0,07 & $(0,000) 4.5$ & $(0,01) 17.8$ \\
\hline Pentraxin-related protein & РTX3 & 1.9 & 3,5 & 1,8 & 0,70 & 0,14 & $(0,000) 4$ & (ns) 2.1 \\
\hline Interstitial collagenase & $\overline{\mathrm{MMP} 1}$ & $\overline{1.7}$ & 4,7 & 2,7 & 0,16 & 0,17 & $\overline{(0,000) 3.4}$ & $\overline{(n s)-1.1}$ \\
\hline $\begin{array}{l}\text { Tumor necrosis factor- } \\
\text { inducible gene } 6 \text { protein }\end{array}$ & $\overline{\text { TNFAIP6 }}$ & $\overline{5.4}$ & 4,8 & 0,9 & 0,95 & 0,20 & $\overline{(0,000) 3.1}$ & $(0, \overline{000) 17.9}$ \\
\hline$\frac{\text { Plasminogen activator }}{\text { inhibitor } 1}$ & SERPINE1 & 1.7 & 4,0 & 2,5 & 0,19 & 0,12 & $\underline{(0,000) 3}$ & (ns) 1.7 \\
\hline C-C motif chemokine 2 & CCL2 & 6.9 & 6,9 & 1,0 & 0,11 & 0,10 & $(0,000) 2.3$ & $(0,004) 3.7$ \\
\hline CD44 antigen & CD44 & 2.4 & 0,3 & 0,1 & 0,01 & 0,02 & (ns) 1.7 & $(0,000) 5.8$ \\
\hline $\begin{array}{l}\text { Insulin-like growth factor- } \\
\text { binding protein } 4\end{array}$ & IGFBP4 & -2.5 & 1,4 & 3,6 & 0,10 & 0,26 & (ns)- 1.1 & (ns) 1.2 \\
\hline $\begin{array}{l}\text { Adipocyte enhancer-binding } \\
\text { protein } 1\end{array}$ & AEBP1 & -1.4 & 0,2 & 0,2 & 0,00 & 0,01 & (ns)- 1.2 & (ns) 1.2 \\
\hline Cystatin-C & CST3 & -3.1 & 0,8 & 2,6 & 0,06 & 0,17 & (ns)-1.2 & (ns) -1.1 \\
\hline Versican core protein & VCAN & -2 & 0,1 & 0,2 & 0,01 & 0,01 & (ns)-1.6 & (ns) -1.4 \\
\hline Collagen alpha-1(VI) chain & COL6A1 & -3.3 & 0,4 & 1,3 & 0,27 & 0,18 & (ns)-1.6 & (ns) -1.4 \\
\hline $\begin{array}{l}\text { Transforming growth factor- } \\
\text { beta-induced protein ig-h3 }\end{array}$ & TGFBI & -2.5 & 0,1 & 0,1 & 0,00 & 0,01 & (ns)-1.6 & (ns) 1 \\
\hline Legumain & LGMN & -3.1 & 0,9 & 2,7 & 0,06 & 0,17 & $(0,002)-2$ & (ns) 1.2 \\
\hline Gelsolin & GSN & -2.5 & 0,1 & 0,4 & 0,03 & 0,02 & $(0.002)-2$ & (ns) 1.1 \\
\hline Cathepsin B & CTSB & -1.2 & 2,2 & 2,7 & 0,04 & 0,04 & (ns) -2 & (ns) -1.2 \\
\hline Lysozyme C & LYZ & -3.3 & 0,1 & 0,3 & 0,01 & 0,04 & $(0,001)-2.5$ & (ns) -3.3 \\
\hline Alpha-2-macroglobulin & $\mathrm{A} 2 \mathrm{M}$ & -3.3 & 0,3 & 1,1 & 0,04 & 0,06 & $(0,000)-3.3$ & (ns) -1.6 \\
\hline
\end{tabular}

Fold change (FC) for the significantly changed proteins ( $p \leq 0.05, F C>1.2)$ in adipose tissue (AT) $n=1$ and the significantly changed genes ( $\leq \leq 0.05, F C>2, n$ $=7$ for adipose tissue and $n=5$ for liver tissue (LT)) is represented in bold, $p$ value is given in brackets (...). The insignificantly affected genes ( $n s)$ are depicted in italics. FC was calculated in LPS treated samples (LPS+) compared to control samples (LPS-). Additionally, information about average (avg) value in proteomics experiment representative for protein expression and its standard deviation (std) are depicted in the table. The top candidate biomarkers related to inflamed adipose tissue are depicted in bold and underlined.

\section{The predicted secretome analysis}

The microarray data analysis of both tissues revealed that adipose and liver tissues have numerous overlapping LPS-responsive genes which protein products are predicted to be secreted. Among these genes we identified several known markers associated with insulin resistance such as IL-6, IL-1 $\beta$, IL-8, and PAI 1. Other proteins known to be upregulated during insulin resistance by adipose tissue [34] such as RANTES, MCP1, PLAUR, CXCL5, were found in our studies to be upregulated in both adipose- and liver tissues. Additionally, in both tissues we found genes, previously shown to be regulated in adipose tissue in relation to insulin resistance: CXCL1, CXCL10, CXCL11, ICAM1, TNFAIP6 [35], FGF2, IL6 [32], and ICAM1, IL-1 [36]. Although TNF $\alpha$ is known to be involved in the development of insulin resistance in both adipose tissue and the liver, it was only significantly upregulated in adipose tissue. However, we observed that 3 out of 5 livers had upregulated expression of TNF $\alpha$ and previously we showed that in liver tissue in vitro, TNF $\alpha$ mRNA level was significantly upregulated after 5 hrs while after $24 \mathrm{hrs}$ the TNF $\alpha$ mRNA level returned to basal values [15,37]. In order to explain this phenomenon we hypothesized that the TNF $\alpha$ response after LPS treatment could be related to number of Kupffer cells (assessed by CD68 expression) or to the expression of TLR4. Thereby, we looked at correlations between TNF $\alpha$ expression and both CD 68 and TLR4. There was no correlation between TNF $\alpha$ expression and CD68, $\mathrm{R}^{2}=0.0063$ (data not shown). The correlation between TNF $\alpha$ and TLR4 indicated on a good positive correlation $\left(R^{2}=0.4\right)$ between these genes and it could indeed explain the observed differences (data not shown). 
Furthermore, the comparative analysis of adipose and liver tissues secretomes in vitro provides a source of candidate biomarkers related to tissue specific inflammation/insulin resistance. Similarly to Shah et al. [35], we identified in the inflamed adipose tissue secretome genes such as: SELE, CD274, ORM1, PLA1A, SLAMF1, CX3CL1, OSM, TNF, C19ORF59, PTX3, IER3, CCL8, CXCL2, SERPINE1, BMP2, FAM107A, GPX3. Moreover, we identified genes of yet unknown functions such as: C14ORF162, C20ORF59 or genes implicated in other than insulin resistance inflammatory diseases: epiregulin, IL-19 or sarcoglycan [38-40].

The analysis of the predicted secretome of inflamed liver tissue revealed several significantly changed genes with a known- and an unknown- relationship to insulin resistance. Identification of biomarkers indicative for inflamed liver tissue could be a useful tool in a diagnosis of NAFLD patients, where the only "golden standard" is an invasive liver biopsy [41]. Biomarkers previously associated with liver diseases and identified in our samples were among others: ANGPTL3, IGFBP2, SDC4, IL1RN $[7,42]$. Examples of other pro-inflammatory proteins affiliated with inflammation but not liver insulin resistance were cathepsin S [34] or granzyme A [43]. In future it has to be validated if the other most differentially regulated genes between both tissues such as: SGCD, LCE3D, EREG, NDP and CXCL9, FSTL3, PDZK1IP1 could be used as biomarkers related to insulin resistance of adipose or liver tissues respectively.

\section{Comparison of transcriptomics and proteomics data}

Finally, the transcriptome data encoding for the adipose tissue inflammatory secretome was validated and compared with the protein data of the inflamed adipose tissue culture medium. The analysis showed that the transcriptome data were in line with the proteomics data, in respect to observed upwards and downwards fold changes (FC) for genes and their corresponding protein products. However, the FC derived from the proteomics experiment cannot be directly compared with the FC of the transcriptome experiment due to substantial technical differences between both technologies. By combination of the comparative transcriptome analysis and proteomics technology we identified leukemia inhibitory factor (LIF), matrix metalopeptidase-1 (MMP-1), pentraxin related gene product (PTX3), fractalkine (CX3CL1), and PAI 1 as the potential set of biomarkers for the inflamed adipose tissue.

Chronic LIF exposure in cardiomyocytes was linked to insulin resistance [44], however the role of LIF in induction of IR in adipose tissue is not known. Proteins of the matrix metalloproteinase (MMP) family are involved in the breakdown of extracellular matrix in normal physiological processes, such as embryonic development, reproduction, and tissue remodelling, as well as in disease processes, such as arthritis and metastasis [45-47]. MMP1 was not reported earlier as a biomarker of IR/ T2D and its role in adipose tissue is not known.

Pentraxin related gene (PTX3) plays a role in innate immunity, inflammation, vascular integrity, fertility, pregnancy, and also in the central nervous system. The PTX3 could influence the development of autoimmune reactions and vascular disorders in humans $[48,49]$. Recently pentraxin was also associated with obesity and metabolic syndrome $[50,51]$ and it was shown to be secreted by adipocytes [52].

Moreover, very recently CX3CL1 (fractalkine) was proposed as a novel human adipochemokine associated with T2D in humans [53].

Other proposed by us candidate biomarkers such as TNF $\alpha$ and SERPINE 1 (PAI) are commonly associated with inflammation, IR, and T2D and are known to be secreted by the stromal vascular fraction of adipose tissue [54].

In summary, based on the obtained data we postulate that during inflammation related to IR the target peripheral tissues (adipose tissue, liver) secret a set of unique proteins which could serve as tissue-specific biomarkers related to the investigated pathology. We believe that our approach of using multiple biomarkers could result in more specific diagnosis for a tissue specific insulin resistance related to inflammation, than the use of single biomarkers.

One of the shortcomings of our study is the use of two different DNA microarray platforms, since the data used here were generated in two different laboratories. However, previous studies comparing human Affymetrix and Illumina platforms show that the obtained results, using the same human material, are highly comparable, especially for genes which are predicted to be differentially expressed [55]. Furthermore, in our studies we compared only genes which were significantly affected and present on both platforms; therefore genes which were not present on both platforms were excluded from the analysis and we did not compare intensities of corresponding genes since they would be different due to the platform specific design. Another possible disadvantage of our studies is application of patients with different gender (the adipose tissue was obtained form females and the liver was derived form males), BMI, age, and other anthropometric and biochemical parameters. However, due to limited access to human tissues we could not control all the parameters according to the proper experimental design. Nevertheless, we are confident that the results presented provide a good basis for future in vivo validation studies.

\section{Conclusions}

In summary, our in vitro approach showed that LPSinduced inflammation in adipose and liver tissues, 
results in upregulation of inflammatory processes and downregulation of metabolic pathways and redox/detoxification reactions. These processes could synergistically contribute to the deregulation of energy homeostasis leading to insulin resistance. Furthermore, our study implies that adipose tissue is more active during inflammation compared to the liver, based on identification of higher number of GO terms and genes involved in inflammation and angiogenesis, and a number of genes predicted to encode for secreted proteins. Whether the identified tissue-specific molecular pathways and the identified candidate biomarkers can be used for tissuespecific diagnosis of insulin resistance in patients awaits further validated in vivo. We believe that this approach may facilitate more targeted treatment of insulin resistance.

\section{Additional material}

Additional file 1: Gene functional classification. Table S1. Gene functional classification-the upregulated adipose tissue transcriptome. Gene functional classification for the upregulated transcripts in adipose tissue $(n=7)$ based on the Database for Annotation, Visualization, and Integrated Discovery (DAVID). Table S2. Gene functional classification-the downregulated adipose tissue transcriptome. Gene functional classification for the downregulated transcripts in adipose tissue $(n=7)$ based on the Database for Annotation, Visualization, and Integrated Discovery (DAVID). Table S3. Gene functional classification-the upregulated liver tissue transcriptome. Gene functional classification for the upregulated transcripts in liver tissue $(n=5)$ based on the Database for Annotation, Visualization, and Integrated Discovery (DAVID). Table S4. Gene functional classification-the downregulated liver tissue transcriptome. Gene functional classification for the downregulated transcripts in liver tissue $(n=5)$ based on the Database for Annotation, Visualization, and Integrated Discovery (DAVID).

Additional file 2: GO analysis. Table S1. GO analysis for the upregulated adipose tissue transcriptome. The significantly upregulated GO terms in adipose tissue $(n=7)$ identified by DAVID. The $\mathrm{GO}$ terms were categorized into broader $\mathrm{GO}$ categories such as: inflammation, development, signaling, metal ion homeostasis, secretion, and angiogenesis. Table S2. GO analysis for the downregulated adipose tissue transcriptome. The significantly downregulated $\mathrm{GO}$ terms in adipose tissue $(n=7)$ identified by DAVID. The GO terms belonged to GO category extracellular matrix. Table S3. GO analysis for the upregulated liver tissue transcriptome. The significantly upregulated $G O$ terms in liver tissue $(n=5)$ identified by DAVID. The GO terms were categorized into broader $\mathrm{GO}$ categories such as: inflammation, development, and angiogenesis. Table S4. GO analysis for the downregulated liver tissue transcriptome. The significantly downregulated $G O$ terms in liver tissue $(n=5)$ identified by DAVID. The $\mathrm{GO}$ terms belonged to $\mathrm{GO}$ categories: amino acid metabolism and inflammation/binding.

Additional file 3: Gene count analysis for the identified GO categories. Table S1. Gene count analysis for the identified GO categories in the significant adipose tissue transcriptome. The significantly upregulated (up) and downregulated (down) genes in adipose tissue (AT), $(n=7)$ within the defined $\mathrm{GO}$ categories (inflammation, development, signaling, metal ion homeostasis, secretion, angiogenesis, and extracellular region. Table S2. Gene count analysis for the identified GO categories in the significant liver tissue transcriptome. The significantly upregulated (up) and downregulated (down) genes in liver tissue (LT), $(n=5)$ within the defined GO categories (inflammation, development, signaling, angiogenesis, amino acid metabolism, and inflammation/binding).

Additional file 4: Secretome prediction. Table S1. The common (overlapping) adipose tissue and liver tissue predicted secretome. The common (overlapping) adipose tissue (AT), $(n=7)$ and liver tissue $(L T),(n=5)$ predicted secretome. The presented genes were significantly changed, $p \leq 0.05$ in both tissues. In the last two columns fold changes (FC) in AT and LT are given. Table S2. The adipose tissue predicted secretome. The adipose tissue (AT) predicted secretome, $(n=7)$. Genes present in AT were significantly changed $(p \leq 0.05, F C>2)$ while the corresponding genes in liver tissue (LT), $(n=5)$ were not significantly affected $(p>0.05)$. Table S3. The liver tissue predicted secretome. The liver tissue (LT) predicted secretome, $\mathrm{n}=5$. Genes present in $\mathrm{LT}$ were significantly changed ( $p \leq 0.05, F C>2)$ while the corresponding genes in adipose tissue (AT), $(n=7)$ were not significantly affected $(p>0.05)$.

\section{Acknowledgements}

We would like to thank Susanne Bauerschmidt and Jan Polman (Merck, Oss, The Netherlands) for the performance and elaboration of the Affymetrix data, Prof. Rainer Breitling for critical discussions and Heleen de Weerd for bioinformatical assistance.

\section{Author details}

${ }^{1}$ Centre for Medical Biomics, University Medical Centre Groningen (UMCG), University of Groningen, Antonius Deusinglaan 1, 9713 AV Groningen, The Netherlands. ${ }^{2}$ Division of Pharmacokinetics, Toxicology and Targeting; Department of Pharmacy University of Groningen, Antonius Deusinglaan 1, 9713 AV Groningen, The Netherlands. ${ }^{3}$ Department of Genetics, University Medical Centre Groningen (UMCG), P.O. Box 30001, 9700 RB Groningen, The Netherlands. ${ }^{4}$ Department of Obstetrics and Gynecology, University Medical Centre Groningen (UMCG), PO Box 30.001, 9700 RB Groningen, The Netherlands. ${ }^{5}$ Wageningen University and Research Centre/RIKILT, Cluster of Toxicology and Effect Analysis, Postbus 230, 6700AE Wageningen, The Netherlands.

\section{Authors' contributions}

ESZ designed the study, wrote the manuscript, performed the statistical analysis, performed adipose tissue culture and adipose tissue and liver tissue processing, MD performed statistical analysis, developed bioinformatics tools, MGLE performed liver tissue slices culture, was involved in data analysis and manuscript revision, DW was involved in proteomics experiments and adipose tissue culture, MdV performed mass spectrometry analysis for protein identification, MB performed Illumina DNA microarrays and was involved in Illumina data processing, AH provided the human adipose tissue, HR was involved in the CILAIR experiment, GMMG revised the manuscript and was involved in the experiments preformed with human liver slices, RJV revised the manuscript. All authors read and approved the final manuscript.

\section{Competing interests}

The authors declare that they have no competing interests.

Received: 28 November 2010 Accepted: 6 October 2011 Published: 6 October 2011

\section{References}

1. Rasouli N, Kern PA: Adipocytokines and the metabolic complications of obesity. J Clin Endocrinol Metab 2008, 93:S64-S73.

2. Hotamisligil GS: Inflammation and metabolic disorders. Nature 2006, 444:860-867.

3. Shoelson SE, Lee J, Goldfine AB: Inflammation and insulin resistance. J Clin Invest 2006, 116:1793-1801.

4. Wellen KE, Hotamisligil GS: Inflammation, stress, and diabetes. J Clin Invest 2005, 115:1111-1119

5. Breitling R: Robust signaling networks of the adipose secretome. Trends Endocrinol Metab 2009, 20:1-7.

6. Karalis KP, Giannogonas P, Kodela E, Koutmani Y, Zoumakis M, Teli T: Mechanisms of obesity and related pathology: linking immune responses to metabolic stress. FEBS J 2009, 276:5747-5754. 
7. Younossi ZM, Gorreta F, Ong JP, Schlauch K, Del GL, Elariny H, Van MA, Younoszai A, Goodman Z, Baranova A, et al: Hepatic gene expression in patients with obesity-related non-alcoholic steatohepatitis. Liver Int 2005, 25:760-771.

8. Edens MA, Kuipers F, Stolk RP: Non-alcoholic fatty liver disease is associated with cardiovascular disease risk markers. Obes Rev 2009, 10:412-419.

9. Virkamaki A, Yki-Jarvinen $\mathrm{H}$ : Mechanisms of insulin resistance during acute endotoxemia. Endocrinology 1994, 134:2072-2078.

10. Virkamaki A, Puhakainen I, Koivisto VA, Vuorinen-Markkola $H$, Yki-Jarvinen $H$ : Mechanisms of hepatic and peripheral insulin resistance during acute infections in humans. J Clin Endocrinol Metab 1992, 74:673-679.

11. Sugita H, Kaneki M, Tokunaga E, Sugita M, Koike C, Yasuhara S, Tompkins RG, Martyn JA: Inducible nitric oxide synthase plays a role in LPS-induced hyperglycemia and insulin resistance. Am J Physiol Endocrinol Metab 2002, 282:E386-E394.

12. Agwunobi AO, Reid C, Maycock $P$, Little RA, Carlson GL: Insulin resistance and substrate utilization in human endotoxemia. J Clin Endocrinol Metab 2000, 85:3770-3778.

13. Bashan N, Kovsan J, Kachko I, Ovadia H, Rudich A: Positive and negative regulation of insulin signaling by reactive oxygen and nitrogen species. Physiol Rev 2009, 89:27-71.

14. Cani PD, Amar J, Iglesias MA, Poggi M, Knauf C, Bastelica D, Neyrinck AM, Fava F, Tuohy KM, Chabo C, et al: Metabolic endotoxemia initiates obesity and insulin resistance. Diabetes 2007, 56:1761-1772.

15. Elferink MG, Olinga P, Draaisma AL, Merema MT, Faber KN, Slooff MJ, Meijer DK, Groothuis GM: LPS-induced downregulation of MRP2 and BSEP in human liver is due to a posttranscriptional process. Am J Physiol Gastrointest Liver Physiol 2004, 287:G1008-G1016.

16. Alvarez-Llamas G, Szalowska E, de Vries MP, Weening D, Landman K, Hoek A, Wolffenbuttel BH, Roelofsen H, Vonk RJ: Characterization of the human visceral adipose tissue secretome. Mol Cell Proteomics 2007, 6:589-600.

17. Dennis G Jr, Sherman BT, Hosack DA, Yang J, Gao W, Lane HC, Lempicki RA DAVID: Database for Annotation, Visualization, and Integrated Discovery. Genome Biol 2003, 4:3.

18. Huang da W, Sherman BT, Lempicki RA: Systematic and integrative analysis of large gene lists using DAVID bioinformatics resources. Nat Protoc 2009, 4:44-57.

19. Jensen $L$, Kuhn M, Stark M, Chaffron S, Creevey C, Muller J, Doerks T, Julien P, Roth A, Simonovic M, et al: STRING 8-a global view on proteins and their functional interactions in 630 organisms. Nucleic Acids Res 2009, 37:D412-D416.

20. Bendtsen JD, Jensen $\sqcup$, Blom N, Von HG, Brunak S: Feature-based prediction of non-classical and leaderless protein secretion. Protein Eng Des Sel 2004, 17:349-356.

21. Roelofsen H, Dijkstra M, Weening D, de Vries MP, Hoek A, Vonk RJ: Comparison of isotope-labeled amino acid incorporation rates (CILAIR) provides a quantitative method to study tissue secretomes. $\mathrm{Mol}$ Cell Proteomics 2009, 8:316-324

22. Swertz MA, Jansen RC: Beyond standardization: dynamic software infrastructures for systems biology. Nat Rev Genet 2007, 8:235-243.

23. Mehta NN, McGillicuddy FC, Anderson PD, Hinkle CC, Shah R, Pruscino L, Tabita-Martinez J, Sellers KF, Rickels MR, Reilly MP: Experimental Endotoxemia Induces Adipose Inflammation and Insulin Resistance in Humans. Diabetes 2009.

24. Wijekoon EP, Skinner C, Brosnan ME, Brosnan JT: Amino acid metabolism in the Zucker diabetic fatty rat: effects of insulin resistance and of type 2 diabetes. Can J Physiol Pharmacol 2004, 82:506-514.

25. She P, Van HC, Reid T, Hutson SM, Cooney RN, Lynch CJ: Obesity-related elevations in plasma leucine are associated with alterations in enzymes involved in branched-chain amino acid metabolism. Am J Physiol Endocrinol Metab 2007, 293:E1552-E1563.

26. Feuerer M, Herrero L, Cipolletta D, Naaz A, Wong J, Nayer A, Lee J, Goldfine AB, Benoist C, Shoelson S, et al: Lean, but not obese, fat is enriched for a unique population of regulatory $T$ cells that affect metabolic parameters. Nat Med 2009, 15:930-939.

27. Nishimura S, Manabe I, Nagasaki M, Eto K, Yamashita H, Ohsugi M, Otsu M, Hara K, Ueki K, Sugiura S, et al: CD8+ effector T cells contribute to macrophage recruitment and adipose tissue inflammation in obesity. Nat Med 2009, 15:914-920.
28. Larsen L, Ropke C: Suppressors of cytokine signalling: SOCS. APMIS 2002, 110:833-844.

29. Lebrun $P$, Van OE: SOCS proteins causing trouble in insulin action. Acta Physiol (Oxf) 2008, 192:29-36.

30. Senn JJ, Klover PJ, Nowak IA, Zimmers TA, Koniaris LG, Furlanetto RW, Mooney RA: Suppressor of cytokine signaling-3 (SOCS-3), a potential mediator of interleukin-6-dependent insulin resistance in hepatocytes. J Biol Chem 2003, 278:13740-13746.

31. Baranova A, Collantes R, Gowder SJ, Elariny H, Schlauch K, Younoszai A, King S, Randhawa M, Pusulury S, Alsheddi T, et al: Obesity-related differential gene expression in the visceral adipose tissue. Obes Surg 2005, 15:758-765.

32. Gomez-Ambrosi J, Catalan V, ez-Caballero A, Martinez-Cruz LA, Gil MJ, Garcia-Foncillas J, Cienfuegos JA, Salvador J, Mato JM, Fruhbeck G: Gene expression profile of omental adipose tissue in human obesity. FASEB $J$ 2004, 18:215-217.

33. Tilg $H$, Moschen AR: Inflammatory mechanisms in the regulation of insulin resistance. Mol Med 2008, 14:222-231.

34. Clement $K$, Langin D: Regulation of inflammation-related genes in human adipose tissue. J Intern Med 2007, 262:422-430.

35. Shah R, Lu Y, Hinkle CC, McGillicuddy FC, Kim R, Hannenhalli S, Cappola TP, Heffron S, Wang X, Mehta NN, et al: Gene profiling of human adipose tissue during evoked inflammation in vivo. Diabetes 2009, 58:2211-2219.

36. Nair S, Lee YH, Rousseau E, Cam M, Tataranni PA, Baier LJ, Bogardus C, Permana PA: Increased expression of inflammation-related genes in cultured preadipocytes/stromal vascular cells from obese compared with non-obese Pima Indians. Diabetologia 2005, 48:1784-1788.

37. Szalowska E, Elferink MG, Hoek A, Groothuis GM, Vonk RJ: Resistin is more abundant in liver than adipose tissue and is not upregulated by lipopolysaccharide. J Clin Endocrinol Metab 2009.

38. Mclntyre E, Blackburn E, Brown PJ, Johnson CG, Gullick WJ: The complete family of epidermal growth factor receptors and their ligands are coordinately expressed in breast cancer. Breast Cancer Res Treat 2009.

39. Commins S, Steinke JW, Borish L: The extended IL-10 superfamily: IL-10, IL-19, IL-20, IL-22, IL-24, IL-26, IL-28, and IL-29. J Allergy Clin Immunol 2008, 121:1108-1111.

40. Sandona D, Betto R: Sarcoglycanopathies: molecular pathogenesis and therapeutic prospects. Expert Rev Mol Med 2009, 11:e28.

41. Byrne CD, Olufadi R, Bruce KD, Cagampang FR, Ahmed MH: Metabolic disturbances in non-alcoholic fatty liver disease. Clin Sci (Lond) 2009 116:539-564

42. Yilmaz $Y$, Ulukaya $E$, Atug $O$, Dolar E: Serum concentrations of human angiopoietin-like protein 3 in patients with nonalcoholic fatty liver disease: association with insulin resistance. Eur J Gastroenterol Hepatol 2009.

43. Pardo J, Aguilo Jl, Anel A, Martin P, Joeckel L, Borner C, Wallich R, Mullbacher A, Froelich CJ, Simon MM: The biology of cytotoxic cell granule exocytosis pathway: granzymes have evolved to induce cell death and inflammation. Microbes Infect 2009, 11:452-459.

44. Florholmen G, Thoresen GH, Rustan AC, Jensen J, Christensen G, Aas V: Leukaemia inhibitory factor stimulates glucose transport in isolated cardiomyocytes and induces insulin resistance after chronic exposure. Diabetologia 2006, 49:724-731.

45. Dos Reis ST, Pontes J Jr, Villanova FE, Borra PM, Antunes AA, Dall'oglio MF, Srougi M, Leite KR: Genetic polymorphisms of matrix metalloproteinases: susceptibility and prognostic implications for prostate cancer. J Urol 2009, 181:2320-2325.

46. Tetu B, Popa I, Bairati I, L'Esperance S, Bachvarova M, Plante M, Harel F, Bachvarov D: Immunohistochemical analysis of possible chemoresistance markers identified by micro-arrays on serous ovarian carcinomas. Mod Pathol 2008, 21:1002-1010.

47. Rosas IO, Richards TJ, Konishi K, Zhang Y, Gibson K, Lokshin AE, Lindell KO Cisneros J, Macdonald SD, Pardo A, et al: MMP1 and MMP7 as potential peripheral blood biomarkers in idiopathic pulmonary fibrosis. PLOS Med 2008, 5:e93.

48. Ortega-Hernandez OD, Bassi N, Shoenfeld Y, Anaya JM: The Long Pentraxin 3 and Its Role in Autoimmunity. Semin Arthritis Rheum 2008.

49. Mantovani A, Garlanda C, Bottazzi B, Peri G, Doni A, Martinez de la TY, Latini R: The long pentraxin PTX3 in vascular pathology. Vascul Pharmacol 2006, 45:326-330. 
50. Ogawa T, Kawano Y, Imamura T, Kawakita K, Sagara M, Matsuo T, Kakitsubata Y, Ishikawa T, Kitamura K, Hatakeyama K, et al: Reciprocal contribution of pentraxin 3 and C-reactive protein to obesity and metabolic syndrome. Obesity (Silver Spring) 2010, 18:1871-1874.

51. Zanetti M, Bosutti A, Ferreira C, Vinci P, Biolo G, Fonda M, Valente M, Cattin L, Guarnieri G, Barazzoni R: Circulating pentraxin 3 levels are higher in metabolic syndrome with subclinical atherosclerosis: evidence for association with atherogenic lipid profile. Clin Exp Med 2009, 9:243-248.

52. Abderrahim-Ferkoune A, Bezy O, Chiellini C, Maffei M, Grimaldi P, Bonino F, Moustaid-Moussa N, Pasqualini F, Mantovani A, Ailhaud G, et al: Characterization of the long pentraxin PTX3 as a TNFalpha-induced secreted protein of adipose cells. J Lipid Res 2003, 44:994-1000.

53. Shah R, Hinkle CC, Ferguson JF, Mehta NN, Li M, Qu L, Lu Y, Putt ME, Ahima RS, Reilly MP: Fractalkine is a novel human adipochemokine associated with type 2 diabetes. Diabetes 2011, 60:1512-1518.

54. Goldberg RB: Cytokine and cytokine-like inflammation markers, endothelial dysfunction, and imbalanced coagulation in development of diabetes and its complications. J Clin Endocrinol Metab 2009, 94:3171-3182.

55. Barnes M, Freudenberg J, Thompson S, Aronow B, Pavlidis P: Experimental comparison and cross-validation of the Affymetrix and Illumina gene expression analysis platforms. Nucleic Acids Res 2005, 33:5914-5923.

\section{Pre-publication history}

The pre-publication history for this paper can be accessed here: http://www.biomedcentral.com/1755-8794/4/71/prepub

doi:10.1186/1755-8794-4-71

Cite this article as: Szalowska et al:: Comparative analysis of the human hepatic and adipose tissue transcriptomes during LPS-induced inflammation leads to the identification of differential biological pathways and candidate biomarkers. BMC Medical Genomics 2011 4:71.

\section{Submit your next manuscript to BioMed Central and take full advantage of:}

- Convenient online submission

- Thorough peer review

- No space constraints or color figure charges

- Immediate publication on acceptance

- Inclusion in PubMed, CAS, Scopus and Google Scholar

- Research which is freely available for redistribution

Submit your manuscript at www.biomedcentral.com/submit 